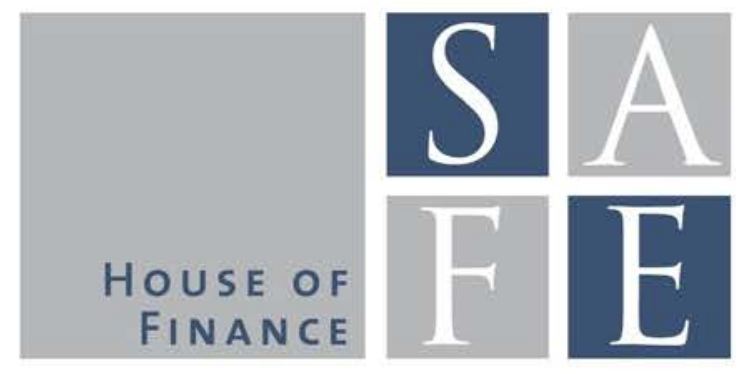

WORKING PAPER SERIES

Benjamin Clapham - Peter Gomber - Jens Lausen - Sven Panz

\title{
Liquidity Provider Incentives in Fragmented Securities Markets
}

SAFE Working Paper No. 231

SAFE I Sustainable Architecture for Finance in Europe A cooperation of the Center for Financial Studies and Goethe University Frankfurt 


\section{Non-Technical Summary}

The introduction of the Markets in Financial Instruments Directive (MiFID I) in Europe has triggered a massively increased fragmentation of securities markets since 2007. Incumbent exchanges and alternative trading venues compete for investors' order flow. Besides a competition based on explicit transaction fees, market operators also implemented specific fee schedules in order to incentivize market participants to increase liquidity provision. Higher liquidity on a securities market lowers implicit transaction costs and thus total transaction costs for market participants.

This paper adds to the literature on liquidity provider incentives and trading fees by analyzing how a single-market incentive program affects liquidity and turnover both on the market introducing the incentive program and on the consolidated market as a whole. Specifically, we investigate the liquidity provider program introduced by Deutsche Börse in October 2016. The program rewards participating market makers on the electronic trading platform Xetra a 100\% fee rebate for liquidity providing orders and quotes in DAX30 instruments if participants fulfill certain obligations concerning quoted volume and presence time at the best bid and offer. In order to assess the effects of the liquidity provider program, we analyze both the perspective of the market introducing the program as well as the perspective of market participants interested in consolidated liquidity since they can access different liquidity pools.

Our results show strong support for the success and effectiveness of liquidity provider incentives for the market that introduces them as it increases market shares and liquidity. This is especially relevant for stocks beyond the most-liquid stocks and thus, in the case of the liquidity provider program investigated in our analysis, a further extension of the program beyond the highly liquid DAX30 stocks could be considered. Moreover, increased liquidity on the venue introducing the incentives also attracts additional trading interest leading to gains in market share at the expense of competing venues.

However, no gains for aggregate liquidity and turnover can be observed. Rather than increasing aggregate liquidity leading to additional trading interest due to lower transaction costs, market participants seem to redistribute liquidity provision and trading activity to the market offering fee rebates for market makers. Consequently, a single-market liquidity provider program, which only links the incentive to quality parameters on that market, increases the respective market's liquidity and market share at the expense of competing venues and does not lead to overall welfare gains in a fragmented market environment. 


\title{
Liquidity Provider Incentives in Fragmented Securities Markets
}

\author{
Benjamin Clapham ${ }^{\mathrm{a}}$, Peter Gomber ${ }^{\mathrm{b}}$, Jens Lausen $^{\mathrm{c}}$, and Sven Panz ${ }^{\mathrm{d}}$ \\ ${ }^{a}$ Goethe University Frankfurt, clapham@wiwi.uni-frankfurt.de \\ ${ }^{\mathrm{b}}$ Goethe University Frankfurt, gomber@wiwi.uni-frankfurt.de \\ ${ }^{\mathrm{c}}$ Goethe University Frankfurt, lausen@wiwi.uni-frankfurt.de \\ ${ }^{\mathrm{d}}$ Goethe University Frankfurt, panz@wiwi.uni-frankfurt.de
}

July 31,2018

\begin{abstract}
We study the introduction of single-market liquidity provider incentives in fragmented securities markets. Specifically, we investigate whether fee rebates for liquidity providers enhance liquidity on the introducing market and thereby increase its competitiveness and market share. Further, we analyze whether single-market liquidity provider incentives increase overall market liquidity available for market participants. Therefore, we measure the specific liquidity contribution of individual markets to the aggregate liquidity in the fragmented market environment. While liquidity and market share of the venue introducing incentives increase, we find no significant effect for turnover and liquidity of the whole market.
\end{abstract}

Keywords: Liquidity, Trading Volume, Market Fragmentation, Liquidity Provider Incentives, Transaction Costs

JEL Classification: G10, G14

We would like to thank Karl Ludwig Keiber, Satchit Sagade and Christian Westheide for helpful comments and suggestions. We also greatly appreciate comments from conference participants at the Annual Meeting of the German Finance Association (DGF) 2017, the Paris Financial Management Conference (PFMC) 2017, and the Annual Meeting of the Swiss Society for Financial Market Research (SGF) 2018. We gratefully acknowledge research support from the research center SAFE, funded by the State of Hessen initiative for research LOEWE, and the E-Finance Lab Frankfurt. 


\section{Introduction}

Since the introduction of the Markets in Financial Instruments Directive (MiFID I) in Europe, incumbent exchanges and alternative trading venues compete for investors' order flow in fragmented securities markets. Besides competing on explicit transaction fees, market operators also implemented specific fee schedules incentivizing liquidity providers in order to increase liquidity and thereby reduce implicit transaction costs and thus total transaction costs for market participants.

On October 4th, 2016, Deutsche Boerse introduced an incentive program on its electronic trading platform Xetra offering fee rebates for liquidity providers. Specifically, participating market makers are rewarded a 100\% fee rebate for passively executed orders and quotes in DAX30 instruments if they fulfill certain obligations concerning quoted volume and presence time at the best bid and offer. The Xetra Liquidity Provider Program (XLP Program) originally started as a pilot but was transferred into a regular pricing scheme immediately after the end of the pilot on March 31st, 2017 (Deutsche Boerse Group, 2017). The goal of the liquidity provider program is to enhance liquidity on Xetra and thus to attract more trading volume due to decreased transaction costs.

The introduction of this market maker scheme on Xetra serves as a quasi-natural experiment to analyze the behavior of market makers and market participants in terms of liquidity provision and trading. Further, it enables to assess how singlemarket liquidity provider incentives influence liquidity and trading volume both on the single market itself and on the fragmented market as a whole. Moreover, this event provides an extraordinary setup as it introduces an adjustment in make fees for specific market participants without any changes in take fees. On the one hand, this analysis is relevant from the perspective of a market operator to assess whether the introduction of liquidity provider incentives is successful in increasing the venue's trading volume and market share. On the other hand, the analysis of a singlemarket liquidity provider program is also highly important from the perspective of market participants caring about aggregate market liquidity of a stock available on different venues as higher aggregate liquidity supply in fragmented markets lowers transaction costs, may ultimately increase total trading volume, and reduces cost of capital for issuers.

Our study relates to other theoretical and empirical contributions analyzing the effects of changes in fee schedules and market maker schemes on trading volume and liquidity. In particular, our results are connected to the empirical findings by Dosanjh (2013) showing that the introduction of market maker incentives in the Australian ETF market significantly improves liquidity. The analysis of this study is also connected to the theoretical considerations of Colliard and Foucault (2012) 
who analyze the effects of competition among markets and reduced trading fees on liquidity. In line with our empirical results, their model also shows that a decrease in make fees ceteris paribus reduces the bid-ask spread.

Our analysis also contributes to research streams analyzing the effects of specific fee schedues and other means to improve the liquidity of a market: Foucault et al. (2013) as well as Malinova and Park (2015) investigate the effects of maker/taker pricing. Foucault et al. (2013) find that differentiating make and take fees can maximize the trading rate and therefore the venue's profit. Moreover, they analyze the optimal use of rebates for market makers from the perspective of the trading venue. Malinova and Park (2015) analyze a change in trading fees on the Toronto Stock Exchange and support the theoretical predictions of Colliard and Foucault (2012). In general, maker/taker pricing schemes are implemented to attract liquidity in times of increased competition due to the entry of new alternative venues (Malinova and Park, 2015). Also, related research analyzes so-called payment for order flow where venues and market makers award brokers with cash payments in order to receive uninformed retail order flow (Battalio and Holden, 2001; Battalio et al., 2001; Parlour and Rajan, 2003). Finally, our study is linked to theoretical and empirical contributions analyzing the value of specialists or designated liquidity providers (Anand and Venkataraman, 2013; Bessembinder et al., 2011; Cao et al., 1997; Panayi et al., 2018; Venkataraman and Waisburd, 2007).

Since we analyze the effects of a single-market liquidity provider incentive program on the consolidated market as a whole, our study also relates to the research stream on market fragmentation. O'Hara and Ye (2011) as well as Gomber et al. (2017) provide comprehensive overviews of existing literature in this field.

To the best knowledge of the authors, this is the first paper consolidating highfrequency order book information of several open limit order book markets to measure the specific liquidity contribution of individual markets to the aggregate liquidity in a fragmented market environment and to analyze how these contributions change after the introduction of single-market liquidity provider incentives. Moreover, we investigate this change in the fee schedule both from the market operator's point of view, who is interested in the venue's own liquidity, trading volume, and market share, as well as from the perspective of market participants caring about aggregate liquidity and trading volume in a fragmented trading landscape.

To analyze the effects of the XLP Program on liquidity and trading volume on Xetra as well as on the aggregate liquidity and trading volume in the fragmented market environment for trading DAX30 instruments in Europe, we apply a difference-indifferences (Imbens and Wooldridge, 2009) approach to exclude possible confounding effects. In our case, the treatment is the introduction of the market maker scheme on Xetra. For the control group, we rely on the highly correlated stocks of the French 
CAC40 index where no changes regarding the main venue's fee schedule for stocks occurred during our observation period covering 100 trading days before and after the treatment.

Our empirical results show that single-market liquidity provider incentives in a fragmented market environment increase liquidity on the respective market in terms of relative spreads, volume at best bid and offer, and order book depth. The program also increases the market's contribution to overall liquidity in the consolidated order book and enables to gain market share in terms of trading volume. However, aggregate trading volume and consolidated liquidity do not significantly rise due to single-market liquidity provider incentives. Rather than increasing overall trading activity and liquidity, our results suggest that market participants redistribute liquidity provision and orders resulting in trade re-allocation to the venue offering fee rebates for market makers.

The remainder of the paper proceeds as follows: Section 2 provides information on the institutional background, the XLP Program, and our data set. Section 3 outlines the research design of our empirical study and presents descriptive statistics. Section 4 presents the results both for the single-market as well as for the multi-market context. The results are discussed in section 5. Finally, section 6 concludes.

\section{Institutional Background and Data Set}

\subsection{Institutional Background}

At the core of our analysis is the XLP Program, a market maker incentive scheme introduced by Deutsche Boerse for trading of stocks in the DAX30 index on its electronic trading platform Xetra. Xetra is an order-driven market with an open limit order book and the main venue for trading DAX30 stocks regarding market share in terms of trading volume denoted in euro (turnover). During our observation period from May 13th, 2016 to February 21st, 2017, the market share of Xetra amounts to $65.62 \%$ of lit trading in DAX30 stocks (Fidessa, 2017). Since we apply a difference-in-differences (DiD) approach to analyze the effects of the XLP Program, we use these DAX30 constituents as the treatment group and the constituents of the highly correlated French CAC40 index as the control group ${ }^{1}$. This control group is predominantly traded on the main market Euronext Paris $(65.35 \%$ market share

1 The CAC40 index shows the highest closing price and turnover correlation to the DAX30 index compared to both the German mid cap index MDAX and other European blue chip indices. See Table A.1 in the appendix. 
during our observation period, Fidessa, 2017) and serves as reference to exclude any confounding effects. In order to investigate the impact of a single-market liquidity provider program on aggregate liquidity and turnover in the fragmented European trading landscape, we add the three largest alternative venues (in terms of turnover in DAX30 and CAC40 stocks) Bats (BS), Chi-X (CHI) ${ }^{2}$, and Turquoise (TQ) to our analysis. Together, these venues cover 98\% (97\%) of turnover in DAX30 (CAC40) instruments in open limit order books during our observation period. The introduction of the XLP Program is the only change in trading rules and transaction fees for DAX30 stocks on Xetra during our observation period. All other considered markets did not introduce any relevant changes during that time.

\subsection{Xetra Liquidity Provider Program}

The goal of the XLP Program is to incentivize liquidity provision at the visible best bid and offer in continuous trading of DAX30 instruments on Xetra. The pilot phase, which was announced on August 22nd, 2016, started on October 4th, 2016. Market makers who want to participate in the program have to sign an additional contract with Deutsche Boerse. For each full month of participation, Deutsche Boerse will grant a $100 \%$ fee rebate for passively executed orders and quotes in DAX30 instruments. In order to qualify for the fee rebates, market participants have to fulfill two monthly requirements: First, the registered market makers (called Xetra Liquidity Providers) have to place orders at the visible best bid and offer with at least 5,000 euro minimum volume on each side with a presence time of at least $20 \%$ during continuous trading. The presence time is averaged across bid and offer of all DAX30 instruments. Second, liquidity providers have to account for a minimum share of $1 \%$ in overall passively executed volume in DAX30 instruments (Deutsche Boerse Group, 2016). ${ }^{3}$ In general, Deutsche Boerse applies no maker/taker pricing for DAX30 instruments on Xetra, therefore the introduction of the XLP Program represents an extraordinary event of an adjustment in make fees for a specific group of registered market makers without any simultaneous change in taker pricing. Compared to other incentive or pricing schemes, liquidity providers are exposed to the risk of not getting any rebates since the rebate requirements are set relative to overall trading and liquidity provision and thus depend on the quoting behavior of other market participants.

2 Both markets Bats and Chi-X were operated by Bats Europe during our observation period. Since February 2017, they are operated by Cboe Europe.

3 For new Xetra Liquidity Providers, the first calendar month of activity serves as a grace period with halved minimum requirements levels (presence time: 10\% with 5,000 euro; passive volume share in DAX30 stocks: $0.5 \%$ ) in order to facilitate a successful start. 
The extension of the pilot into a regular pricing scheme with identical parameters was announced on February 17th, 2017, and started on April 3rd, 2017. Therefore, it directly succeeded the pilot phase (Deutsche Boerse Group, 2017).

\subsection{Data Set}

For the empirical investigations, we use Thomson Reuters Tick History (TRTH) data including high-frequent trade and order book information. Due to the fact that the XLP Program is applied for DAX30 instruments only, the constituents of this index traded on Xetra are our main subject of interest. To derive robust results on the effects of the liquidity provider incentives, we consider different observation windows up to 100 trading days before and after the start of the XLP Program. Therefore, our observation period lasts from May 13th, 2016 to February 21st, 2017. ${ }^{4}$ We exclude the stocks of Deutsche Boerse AG and Technip SA due to merger activities as well as the stock of Valeo SA because of data issues. Consequently, the analysis is based on 29 DAX30 and 38 CAC40 constituents.

For each constituent of the DAX30 and the CAC40, we construct a synthetic consolidated order book, in which we merge all orders and trades from the main market with those from the three alternative venues on a tick-by-tick basis. ${ }^{5}$ Recent studies applied different methodologies to develop a consolidated limit order book. Gresse (2017) determines the highest bid and the lowest ask price across all competing markets for each second. Foucault and Menkveld (2008) build five minute snapshots of the consolidated limit order book across markets. Similarly, Degryse et al. (2015) take snapshots of the ten best bid and ask prices and their associated quantities for every minute and each stock venue combination for their consolidated limit order book.

We go further by applying a sophisticated approach in which we construct a consolidated limit order book based on each tick-by-tick record of all order books to obtain a much more accurate picture of the consolidated market. This is especially important since order book updates become more and more frequent so that high-level aggregations do not include all relevant information. For this purpose, we consider 15 limit levels for the consolidated book on the bid and ask side and merge the prices as well as the respective volumes of all venues. In order to determine trade

4 We consider all trading days where trading is possible in DAX30 and CAC40 instruments, i.e., we drop two trading days of the CAC40 sample which are public holidays in Germany resulting in the same 200 trading days for each sample.

5 Thomson Reuters reports no changes regarding granularity and quality of the considered data feeds for the whole observation period. 
related parameters, we also consolidate transaction information by merging all trade records of all four venues in our data set.

Based on our consolidated limit order book and consolidated trades, we aggregate the following information on a daily basis: turnover during continuous trading, relative quoted spreads, euro volume at the best bid and offer (L1-Volume), euro volume at lower levels of the order book, i.e., order book levels two to ten (L2to10Volume), and order book depth $(\operatorname{Depth}(10))$ as our main variables of interest. In addition, we calculate the contributions of the main market to aggregate turnover, to the best available bid and offer in the consolidated market ("European best bid and offer", EBBO), to consolidated L1-Volume, and to consolidated order book depth. We enrich our data set with the market capitalizations and the minimum tick sizes of the stocks on the main venues Xetra and Euronext to divide our data set in different subsamples. Moreover, we use the minimum tick size to investigate whether the share of main market quotes that are equal to the minimum tick size changes due to the XLP program.

\section{Research Design and Descriptive Statistics}

\subsection{Methodology}

For the analysis of the XLP Program, we rely on the difference-in-differences method, which is widely used in empirical market microstructure research to assess the effects of changes in market design, market regulation, and trading technology (e.g., Battalio and Schultz, 2011; Hendershott et al., 2011). In this setup, we observe a treatment and a control group in two periods while only the first group is affected by a treatment in the second period. This procedure allows us to analyze the treatment (i.e., the new incentive scheme for liquidity providers) independent of biases due to trends in the treatment group over time and permanent differences between both groups (Imbens and Wooldridge, 2009).

Our regression setup for the DiD-approach takes the following form:

$$
Y_{i, t}=\alpha_{i}+\beta_{1} \cdot \text { Post }_{t}+\beta_{2} \cdot D A X_{i} \cdot \text { Post }_{t}+\sum_{k=3}^{6} \beta_{k} \cdot \text { Day }_{i, t}+\varepsilon_{i, t} .
$$

$Y_{i, t}$ captures each dependent liquidity or turnover parameter introduced in the next subsection, where $i$ denotes the respective stock and $t$ the respective observation day. $D A X_{i}$ is a dummy variable being 1 if the individual stock is in the treatment group (i.e., the stock is listed in the DAX30 and affected by the new liquidity provider 
incentives on Xetra) and 0 otherwise. Similarly, Post $_{t}$ is a dummy variable accounting for the pre- $(0)$ and post-treatment (1) periods, which are separated by the date of the introduction of the XLP Program (October 4th, 2016). We further control for weekdays, which are represented by a dummy variable $D a y_{i, t}$. The variable $\varepsilon_{i, t}$ equals the idiosyncratic error term. The results of the panel regression are derived using stock fixed effects estimators to eliminate time-constant and unobserved effects as proposed by Wooldridge (2002), where $\alpha_{i}$ is the constant, depending on stock $i$. We do not consider a single $D A X_{i}$ dummy in the regression setup, since it does not vary over time and would be dropped due to fixed effects.

The DAX30 index and the CAC40 index, whose constituents serve as a control group, show strong similarities concerning the evolution of closing prices (closing price correlation in the complete observation period of 97.5\%) and constituent turnover correlation (in the complete observation period of $89.5 \%$ ) as shown in Table A.1 in the appendix. Furthermore, both indices share similar levels of fragmentation. While the DAX30 has a fragmentation of 2.31, the CAC40 has a fragmentation of 2.27 measured by the inverse of the Herfindahl-Hirschman Index for the whole observation period (Fidessa, 2017). Since treatment and control group show strong similarities, controlling for further variables (e.g., volatility, liquidity, etc.) is not necessary.

For the general research setup, we focus on an observation period of 100 days ("longterm") before and after the introduction of the XLP Program. To further add robustness to our analysis as well as to differentiate between short-term and long-term effects, we repeat our analysis for observation windows of ten days ("short-term") and 50 days ("medium-term") around the introduction of the liquidity provider incentives on Xetra. Further, for the 100 days period, we divide the stocks of the two indices in three nearly ${ }^{6}$ equally sized subsamples (S1, S2, and S3) in order to compare similar instruments concerning market capitalization and percentage of quotes that are equal to the minimum tick size 7 ("large", "medium", "small") as depicted in Table 1. This approach allows to determine whether any of the observed effects depends on specific groups of stocks since it enables a distinct assignment of changes in turnover and liquidity to certain market segments according to market capitalization and share of quotes at minimum tick size.

6 The three subsamples are nearly equally sized since we observe 29 DAX30 stocks and 38 CAC40 stocks.

7 The tick size regime applied by Xetra and Euronext during our observation period is provided in Table A.2 in the appendix. The calculation of the share of quotes at minimum tick size is shown in Table A.3 in the appendix. 


\begin{tabular}{|c|c|c|c|c|c|c|c|c|}
\hline \multicolumn{9}{|c|}{$\begin{array}{l}\text { Subsamples According to Market Capitalization and Share of Quotes at Minimum Tick Size } \\
\end{array}$} \\
\hline \multicolumn{9}{|c|}{$\begin{array}{l}\text { This table reports the analyzed DAX30 and CAC40 index constituents categorized in thirds by market capitalisation } \\
\text { (in billion euro) and share of main market quotes at minimum tick size (in percent). Market capitalization is reported } \\
\text { as of October 4th, } 2016 \text { when the XLP Program was introduced while the percentage of quotes at minimum tick } \\
\text { size is computed for the } 100 \text { days before the event (MinTickShare). S1 (S3) denotes the subsample with the highest } \\
\text { (lowest) market capitalization and percentage of quotes at minimum tick size. The stock name is the respective } \\
\text { Thomson Reuters Instrument Code for the main venue. }\end{array}$} \\
\hline & \multicolumn{4}{|c|}{ DAX30 } & \multicolumn{4}{|c|}{ CAC40 } \\
\hline & \multicolumn{2}{|c|}{ Market capitalization } & \multicolumn{2}{|c|}{ MinTickShare } & \multicolumn{2}{|c|}{ Market capitalization } & \multicolumn{2}{|c|}{ MinTickShare } \\
\hline \multirow{13}{*}{ S1 } & SAPG.DE & 100.09 & ALVG.DE & 73.48 & TOTF.PA & 107.91 & LVMH.PA & 70.30 \\
\hline & SIEGn.DE & 89.63 & DTEGn.DE & 55.49 & OREP.PA & 95.36 & ORAN.PA & 68.54 \\
\hline & BAYGn.DE & 74.45 & HNKG_p.DE & 54.29 & SASY.PA & 88.93 & ESSI.PA & 66.11 \\
\hline & BASFn.DE & 71.26 & ADSGn.DE & 49.15 & LVMH.PA & 79.51 & VIV.PA & 61.91 \\
\hline & DTEGn.DE & 69.21 & LING.DE & 46.00 & BNPP.PA & 57.37 & ENGIE.PA & 61.34 \\
\hline & DAIGn.DE & 68.87 & MUVGn.DE & 45.49 & AXAF.PA & 45.99 & OREP.PA & 52.82 \\
\hline & ALVG.DE & 60.76 & SIEGn.DE & 43.43 & DANO.PA & 44.19 & PEUP.PA & 50.42 \\
\hline & BMWG.DE & 46.53 & VOWG_p.DE & 43.00 & AIR.PA & 42.38 & PERP.PA & 49.87 \\
\hline & FREG.DE & 39.06 & LHAG.DE & 39.17 & SGEF.PA & 40.83 & SASY.PA & 47.63 \\
\hline & CONG.DE & 37.74 & DBKGn.DE & 37.44 & AIRP.PA & 37.75 & AXAF.PA & 45.69 \\
\hline & & & & & ORAN.PA & 37.36 & PRTP.PA & 45.69 \\
\hline & & & & & SCHN.PA & 36.73 & SGEF.PA & 45.32 \\
\hline & & & & & ENGIE.PA & 30.71 & VIE.PA & 44.26 \\
\hline \multirow{12}{*}{$\mathrm{S} 2$} & DPWGn.DE & 33.78 & IFXGn.DE & 35.79 & NOKIA.PA & 30.23 & DANO.PA & 41.88 \\
\hline & ADSGn.DE & 32.93 & SAPG.DE & 27.42 & LHN.PA & 29.37 & UNBP.AS & 39.19 \\
\hline & LING.DE & 28.58 & DPWGn.DE & 25.92 & PERP.PA & 28.59 & CARR.PA & 38.91 \\
\hline & MUVGn.DE & 26.57 & DAIGn.DE & 25.70 & SAF.PA & 27.72 & EXHO.PA & 36.57 \\
\hline & VOWG_p.DE & 24.46 & CONG.DE & 25.23 & ESSI.PA & 25.03 & AIR.PA & 35.49 \\
\hline & FMEG.DE & 23.70 & BASFn.DE & 22.70 & CAGR.PA & 24.97 & SCHN.PA & 31.65 \\
\hline & HNKG_p.DE & 21.90 & RWEG.DE & 19.31 & SOGN.PA & 24.96 & TOTF.PA & 31.57 \\
\hline & BEIG.DE & 21.38 & BAYGn.DE & 17.94 & UNBP.AS & 23.60 & PUBP.PA & 29.84 \\
\hline & IFXGn.DE & 18.11 & FREG.DE & 14.42 & PRTP.PA & 23.56 & SAF.PA & 29.01 \\
\hline & & & & & VIV.PA & 23.26 & LEGD.PA & 24.09 \\
\hline & & & & & RENA.PA & 22.35 & SGOB.PA & 23.57 \\
\hline & & & & & SGOB.PA & 21.51 & AIRP.PA & 22.32 \\
\hline \multirow{13}{*}{ S3 } & HEIG.DE & 16.80 & PSMGn.DE & 12.60 & MICP.PA & 18.05 & BOUY.PA & 19.01 \\
\hline & DBKGn.DE & 16.20 & BMWG.DE & 12.12 & CARR.PA & 17.69 & MICP.PA & 16.16 \\
\hline & VNAn.DE & 15.52 & TKAG.DE & 10.00 & ISPA.AS & 16.82 & SOGN.PA & 15.32 \\
\hline & EONGn.DE & 12.53 & VNAn.DE & 9.37 & EXHO.PA & 16.56 & CAPP.PA & 15.31 \\
\hline & MRCG.DE & 12.47 & HEIG.DE & 8.98 & PUBP.PA & 15.22 & BNPP.PA & 14.75 \\
\hline & TKAG.DE & 12.14 & FMEG.DE & 7.40 & CAPP.PA & 15.22 & ACCP.PA & 14.46 \\
\hline & RWEG.DE & 8.79 & EONGn.DE & 6.27 & LEGD.PA & 14.01 & SOLB.BR & 14.02 \\
\hline & PSMGn.DE & 8.46 & MRCG.DE & 5.26 & LOIM.PA & 12.57 & LOIM.PA & 13.50 \\
\hline & CBKG.DE & 7.28 & BEIG.DE & 4.70 & VIE.PA & 11.42 & ISPA.AS & 11.82 \\
\hline & LHAG.DE & 4.52 & CBKG.DE & 4.32 & PEUP.PA & 11.21 & RENA.PA & 11.30 \\
\hline & & & & & SOLB.BR & 10.94 & CAGR.PA & 5.71 \\
\hline & & & & & BOUY.PA & 10.34 & LHN.PA & 2.20 \\
\hline & & & & & ACCP.PA & 10.20 & NOKIA.PA & 1.97 \\
\hline
\end{tabular}

Table 1: Subsamples of analyzed stocks according to market capitalization and percentage of pre-event quotes at minimum tick size. 


\subsection{Analyzed Liquidity and Turnover Parameters}

In order to evaluate the effects of introducing a liquidity provider program both on the single market itself as well as on the fragmented market as a whole, we split the analyzed liquidity and turnover parameters in two groups: First, we focus on the view of the exchange operator introducing the program and analyze how turnover and liquidity measures on his own market (here: Xetra) are affected. Second, we turn to the view of market participants caring about market liquidity as a whole and analyze how the single-market liquidity provider program influences aggregate (European) turnover and consolidated liquidity. The target of this separation is to analyze possible benefits of such a program for the exchange introducing the incentives and the participants in the consolidated market separately.

For both views, we include the daily average of liquidity and turnover parameters. In order to analyze liquidity, we rely on the quoted relative spread as a measure of liquidity supply. The relative spread represents a market's costs of immediacy, which compensate traders for providing liquidity, and is a key measure to assess the quality of a securities market. Additionally, we analyze the share of main market quotes that are equal to the minimum tick size (MinTickShare), which represents the share of quotes that exhibit the minimum possible bid-ask spread. Therefore, these quotes have no room for further spread improvements. Since the XLP Program requires market participants to quote sufficient volume at the best bid and offer in order to qualify for the fee rebates, we consider the euro volume available at the best bid and offer (L1-Volume), calculated by the sum of the best bid and best ask price times quoted volume at the first level of the order book. Additionally, we include the euro volume available beneath the best bid and offer at the order book levels two to ten (L2to10-Volume) to analyze whether an increase in order book volume at the top of the order book is due to additional quoted volume or due to orders that were shifted from lower levels to the top of the order book to fulfill rebate requirements.

In order to account for liquidity deeper in the order book, we also include the depth measure as proposed by Degryse et al. (2015). Depth $(X)$ measures the order volume available $X$ basis points (bps) around the midpoint in euro. This measure indicates a market's ability to absorb large orders without leading to subsequent order imbalances and price variability. A high depth measure indicates a more resilient market which is able to dampen execution-based market price impact more effectively than a market with a lower depth. In line with Degryse et al. (2015), we use the depth measure with $X=10$ bps around the midpoint (Depth(10)).

Since the obligations of the XLP Program for market participants are connected to continuous trading, we do not include auction turnover in our analysis. Therefore, 
we consider turnover during continuous trading (calculated as the sum of traded volume times the execution price).

For the perspective of the single market and the market operator executing the liquidity provider program, we calculate the mentioned parameters for the main market Xetra (respectively Euronext Paris for the control group) only. The purpose of this approach is to analyze how the liquidity provider program changes liquidity and turnover of the main market in order to assess possible benefits for the single market, its operator, and its participants. Further, we include parameters concerning the contribution of the main venue to the consolidated market. Therefore, we consider the share of the main venue to the consolidated best bid and offer (EBBOShare) as well as the contribution of the main market to consolidated order book depth (Depth(10)Share), L1-Volume in euro (L1-VolumeShare), and aggregate turnover (MarketShare). We use these parameters to analyze whether the liquidity provider incentives have an impact on the market share of the main venue or on the contribution of the main market to consolidated liquidity. All analyzed liquidity and turnover parameters are summarized in Table A.3 in the appendix.

In order to assess possible benefits for market participants in the fragmented market as a whole, we determine the liquidity and turnover parameters for the consolidated market. The purpose of this analysis is to reveal whether single-market liquidity provider incentives have an impact on the consolidated market in terms of liquidity and overall traded volume, and, as a consequence, whether this benefits market participants who are able to access multiple liquidity pools. All parameters are calculated for each combination of stock and day. We provide the respective results within separate regressions for each market quality parameter.

\subsection{Descriptive Statistics}

Figure 1 plots turnover, relative spread, L1-Volume and order book depth of the consolidated market based on the parameter's daily mean averaged for each index separately and plotted for our whole observation period of 100 trading days before and after the introduction of the XLP Program. This figure also provides support for our DiD-approach. Sharp spikes as in turnover and relative spreads or drops in volume-based liquidity measures would bias a normal regression setup significantly. By applying a DiD-approach, we explicitly control for such events and also for general trends. The descriptive analysis of the four consolidated measures already indicates that the development of the parameters for both indices exhibits very similar patterns. Thus, the CAC40 stocks represent a suitable control group for our DiD-approach. 
The spikes in turnover, respectively the drops in liquidity can be traced back to extraordinary events within our observation period. For example, on June 24th, 2016, the result of the UK referendum to leave the European Union lead to a dramatic reaction of the German (French) market, with opening prices down by up to $10 \%$ (8\%). Likewise, the presidential election in the US in November 2016 caused market-wide uncertainty.
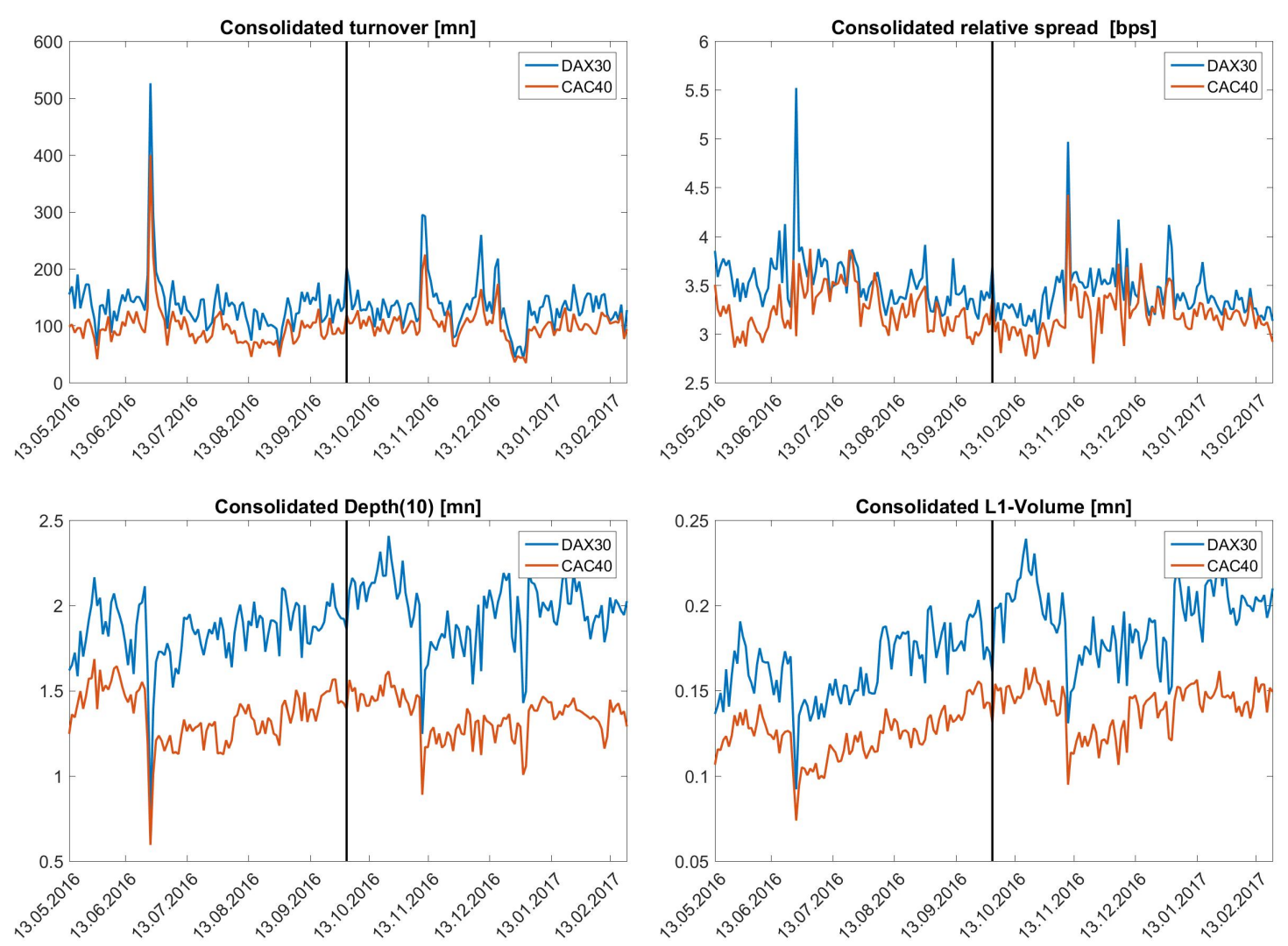

Cross-sectional average of consolidated turnover and liquidity measures separately for each day and index. The black line in the middle of the observation period indicates the start of the XLP Program on October 4 th, 2016.

Figure 1: Turnover and liquidity measures of the consolidated market.

Besides the influence of the liquidity provider program on consolidated turnover and liquidity, we also investigate its implications for the main market. A detailed breakdown of the considered measures for each single venue can be found in Figure A.1 in the appendix. Figure 2 highlights the improvements in market share, the share of the main market showing the $\mathrm{EBBO}$, and the share of the main market in consolidated L1-Volume and order book depth. Even relative to the control group, all contributions of Xetra improve after the introduction of the XLP Program. 

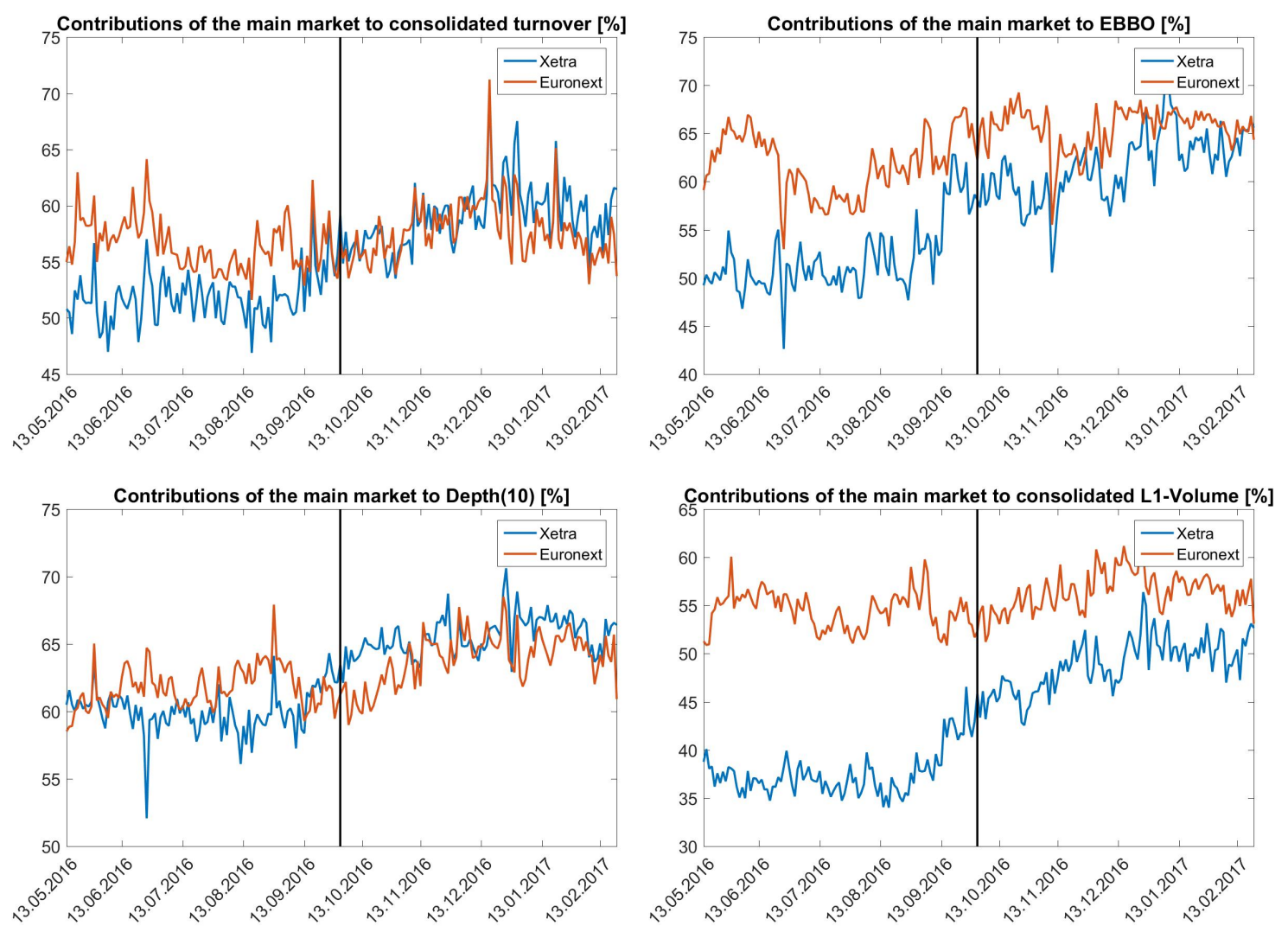

Cross-sectional average of the respective main venue's contribution to aggregate turnover and liquidity of the consolidated market. The black line in the middle of the observation period indicates the start of the XLP

Program on October 4th, 2016.

Figure 2: Contribution of the main market to consolidated turnover and liquidity.

Table 2 reports the changes in liquidity and turnover on both main markets Xetra and Euronext after the introduction of the XLP Program on Xetra. The DiD parameter shows the difference between the percentage changes of Xetra and Euronext for each measure and is, therefore, a first descriptive indicator for the actual effect of the XLP Program on liquidity and turnover. Regarding turnover, only a small increase of 1.28 percentage points can be traced back to the XLP Program as shown by the DiD parameter. Although turnover on Xetra rises by on average $8.72 \%$ after the introduction of the fee rebates, only a small portion of the increase is attributable to the XLP Program since the percentage change is almost equal on Euronext from the pre- to the post-treatment period. For the other variables measuring different dimensions of liquidity, the DiD parameter shows high improvements in liquidity on Xetra that are attributable to the liquidity provider incentives. On average, the relative spread in the post-treatment period tightens on Xetra and decreases by 8.09 percentage points more than the average relative spread on Euronext. Order book depth also clearly improves by 13.29 percentage points more on Xetra than in the 
control group. Also, the percentage of quotes at minimum tick size (MinTickShare) increases by 6.78 percentage points more on Xetra relative to Euronext indicating that liquidity providers set the spread more often to the lowest possible value due to the XLP Program. The same holds for L1-Volume which increases by 16.63 percentage points more on Xetra than on Euronext. Since the euro volume on lower levels of the order book (L2to10-Volume) decreases only marginally by 1.40 percentage points relative to Euronext, volume at the top of the order book appears to be mainly due to additional liquidity provision to Xetra and not the result of shifted orders from lower levels to the top.

\begin{tabular}{|c|c|c|c|c|c|}
\hline \multicolumn{6}{|c|}{ Changes in Liquidity and Turnover of the Main Venue } \\
\hline \multicolumn{6}{|c|}{$\begin{array}{l}\text { This table reports the analyzed turnover and liquidity measures of the main } \\
\text { markets Xetra and Euronext averaged across } 100 \text { days before and } 100 \text { days } \\
\text { after the introduction of the XLP Program. Turnover, L1-Volume, L2to10- } \\
\text { Volume, and Depth(10) are reported in millions, relative spread is denoted } \\
\text { in basis points, and MinTickShare is shown in percent. }\end{array}$} \\
\hline & & Pre & Post & \%Change & $\mathrm{DiD}$ \\
\hline \multirow{2}{*}{ Turnover } & Xetra & 72.20 & 78.50 & $8.72 \%$ & \multirow{2}{*}{$1.28 \%$} \\
\hline & Euronext & 54.93 & 59.02 & $7.44 \%$ & \\
\hline \multirow{2}{*}{ Relative Spread } & Xetra & 4.93 & 4.39 & $-10.93 \%$ & \multirow{2}{*}{$-8.09 \%$} \\
\hline & Euronext & 4.19 & 4.07 & $-2.85 \%$ & \\
\hline \multirow{2}{*}{$\operatorname{Depth}(10)$} & Xetra & 1.08 & 1.25 & $16.07 \%$ & \multirow{2}{*}{$13.29 \%$} \\
\hline & Euronext & 0.83 & 0.86 & $2.78 \%$ & \\
\hline \multirow{2}{*}{ L1-Volume } & Xetra & 0.10 & 0.13 & $28.80 \%$ & \multirow{2}{*}{$16.63 \%$} \\
\hline & Euronext & 0.09 & 0.11 & $12.17 \%$ & \\
\hline \multirow{2}{*}{ L2to10-Volume } & Xetra & 2.82 & 3.17 & $12.53 \%$ & \multirow{2}{*}{$-1.40 \%$} \\
\hline & Euronext & 1.79 & 2.04 & $13.93 \%$ & \\
\hline \multirow{2}{*}{ MinTickShare } & Xetra & 26.98 & 35.66 & $32.16 \%$ & \multirow{2}{*}{$6.78 \%$} \\
\hline & Euronext & 32.88 & 41.23 & $25.38 \%$ & \\
\hline
\end{tabular}

Table 2: Changes in liquidity and turnover of the main venue 100 days around the introduction of the XLP Program.

Most noticeable are the changes in the percentage-wise contribution of the main market to the aggregate, consolidated measures as shown in Table 3. The DiD parameter shows similar patterns for market share and contribution of Xetra to the consolidated best bid and offer. Specifically, the descriptive analysis indicates substantial gains of Xetra in market share as well as increased contribution to the consolidated best bid and offer compared to Euronext amounting to 11.34 and 12.20 percentage points respectively. In particular, the contribution of the main market to the consolidated L1-Volume improves by $29.8 \%$, while the control group only improves by $3.59 \%$. The contribution to Depth(10) of the consolidated market, which also considers deeper order book levels, increases less and is only 5.78 percentage points higher for Xetra compared to Euronext. 


\begin{tabular}{|c|c|c|c|c|c|}
\hline \multicolumn{6}{|c|}{ Contribution of the Main Venue to the Consolidated Market } \\
\hline \multicolumn{6}{|c|}{$\begin{array}{l}\text { This table reports the contribution of the main markets Xetra and Eu- } \\
\text { ronext to the aggregate turnover and liquidity in the consolidated market } \\
\text { for DAX30 and CAC40 stocks averaged across } 100 \text { days before and } 100 \text { days } \\
\text { after the introduction of the XLP Program. }\end{array}$} \\
\hline & & Pre & Post & \%Change & DiD \\
\hline \multirow{2}{*}{ Market Share } & Xetra & $\overline{51.97 \%}$ & $59.02 \%$ & $13.57 \%$ & \multirow{2}{*}{$11.34 \%$} \\
\hline & Euronext & $56.54 \%$ & $57.80 \%$ & $2.23 \%$ & \\
\hline \multirow{2}{*}{ EBBO Share } & Xetra & $52.00 \%$ & $61.57 \%$ & $18.41 \%$ & \multirow{2}{*}{$12.20 \%$} \\
\hline & Euronext & $61.73 \%$ & $65.57 \%$ & $6.21 \%$ & \\
\hline \multirow{2}{*}{$\operatorname{Depth}(10)$ Share } & Xetra & $60.03 \%$ & $65.62 \%$ & $9.30 \%$ & \multirow{2}{*}{$5.78 \%$} \\
\hline & Euronext & $61.75 \%$ & $63.92 \%$ & $3.52 \%$ & \\
\hline \multirow{2}{*}{ L1-Volume Share } & Xetra & $37.66 \%$ & $48.88 \%$ & $29.80 \%$ & \multirow{2}{*}{$26.20 \%$} \\
\hline & Euronext & $54.47 \%$ & $56.42 \%$ & $3.59 \%$ & \\
\hline
\end{tabular}

Table 3: Contribution of the main venue to the consolidated market 100 days around the introduction of the XLP Program.

Table 4 highlights the differences from the pre- to the post-treatment period for the consolidated market. The DiD parameter shows similar patterns for the liquidity measures, but the improvements are significantly lower compared to the singlemarket perspective. Aggregate turnover, however, even exhibits a negative percentage change from the pre- to the post-treatment period resulting in a negative DiD parameter as aggregate turnover for CAC40 stocks increases in the same period. Consequently, this first descriptive analysis shows that while minor improvements in liquidity are observable, gains in market share of Xetra are at the expense of competing venues.

\begin{tabular}{|c|c|c|c|c|c|}
\hline \multicolumn{6}{|c|}{ Changes in Liquidity and Turnover in the Consolidated Market } \\
\hline \multicolumn{6}{|c|}{$\begin{array}{l}\text { This table reports the analyzed turnover and liquidity measures of the con- } \\
\text { solidated market for DAX30 and CAC40 stocks averaged across } 100 \text { days } \\
\text { before and } 100 \text { days after the introduction of the XLP Program. Turnover, } \\
\text { L1-Volume, and Depth(10) are reported in millions, relative spread is de- } \\
\text { noted in basis points. }\end{array}$} \\
\hline & & Pre & Post & \%Change & $\mathrm{DiD}$ \\
\hline \multirow{2}{*}{ Turnover } & DAX30 & 138.22 & 132.99 & $-3.79 \%$ & \multirow{2}{*}{$-9.37 \%$} \\
\hline & CAC40 & 96.47 & 101.86 & $5.59 \%$ & \\
\hline \multirow{2}{*}{ Relative Spread } & DAX30 & 3.54 & 3.40 & $-3.96 \%$ & \multirow{2}{*}{$-2.13 \%$} \\
\hline & $\mathrm{CAC} 40$ & 3.25 & 3.19 & $-1.83 \%$ & \\
\hline \multirow{2}{*}{$\operatorname{Depth}(10)$} & DAX30 & 1.84 & 1.97 & $6.87 \%$ & \multirow{2}{*}{$7.37 \%$} \\
\hline & CAC40 & 1.35 & 1.35 & $-0.50 \%$ & \\
\hline \multirow{2}{*}{ L1-Volume } & DAX30 & 0.16 & 0.19 & $17.71 \%$ & \multirow{2}{*}{$4.26 \%$} \\
\hline & CAC40 & 0.12 & 0.14 & $13.44 \%$ & \\
\hline
\end{tabular}

Table 4: Changes in liquidity and turnover in the consolidated market 100 days around the introduction of the XLP Program. 
The descriptive parameters for the shorter observation periods of 50 days and ten days around the introduction of the XLP Program are provided in Tables A.4 to A.9 in the appendix. The descriptive results for the 50 days and ten days observation windows show a similar picture to the whole observation period although some of the effects are lower for shorter observation windows around the introduction of the XLP Program.

In order to validate our consolidation procedure, we plot the percentage of crossed order book situations (best bid $>$ best ask) and the percentage of locked order book situations (best bid = best ask) of the consolidated order book in Figure 3 on a daily basis for the whole observation period. The percentage share of locked order book situations with consolidated bid and ask being equal varies between $4 \%$ and $8 \%$ and exhibits a relatively stable pattern over the observation period. Crossed order book snapshots indicate arbitrage possibilities (neglecting any transaction fees). In times of high-frequency trading and traders applying inter-market arbitrage strategies, these situations should be relatively rare and should particularly not persist for a long time. Indeed, the share of crossed order book situations in our consolidated book is very low and fluctuates between $0.2 \%$ and $1.4 \%$, exceeding $0.8 \%$ on only two days. Therefore, we can claim that our consolidation approach is valid and achieves reasonable results.
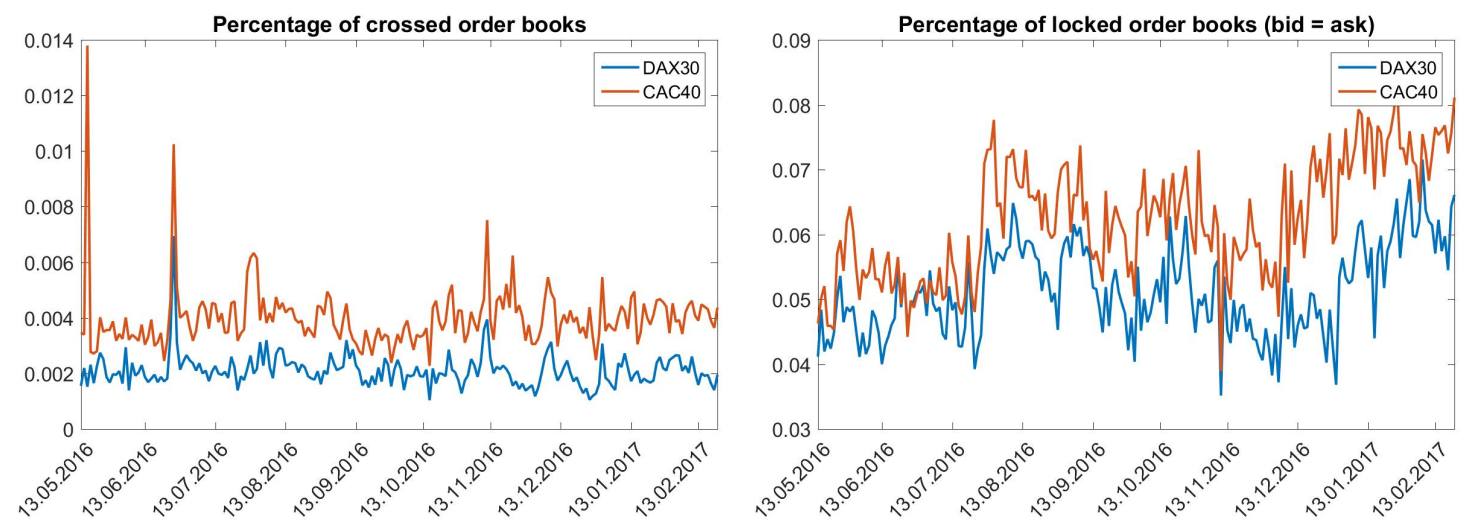

Figure 3: Share of crossed and locked order book situations in the consolidated order book. 


\section{Empirical Results}

\subsection{The Effect of the XLP Program on Liquidity and Turnover on Xetra}

From the single-market perspective, the introduction of the liquidity provider program aims at increasing liquidity and turnover on Xetra. Consequently, in the first application of the aforementioned DiD-approach, we use turnover and liquidity measures for DAX30 constituents on Xetra (treatment group) as well as for CAC40 stocks on the corresponding main market Euronext (control group). Table 5 reports the results of the panel regressions regarding changes in turnover during continuous trading (Turnover) as well as differences in relative spreads (RelativeSpread), percentage of quotes at minimum tick size (MinTickShare), order book depth (Depth(10)), euro volume available at the best bid and offer (L1-Volume), and euro volume at order book levels two to ten (L2to10-Volume). The reported values represent the $\beta_{2}$ coefficient from Equation 1 for each liquidity and turnover parameter, which is the coefficient of interest for the DiD approach.

In fact, the results of the DiD-regression show that relative spreads on Xetra decrease significantly after the introduction of the liquidity provider program even when controlling for possible confounding effects via the control group of trading in CAC40 stocks on Euronext. This observation is indicated by the negative and significant coefficient of the panel regression's interaction term for the observation windows of 100 and 50 days around the event. For the time frame of ten days, we also observe a reduction in relative spreads, however, the decrease is not statistically significant. Moreover, the effect gains in magnitude from ten days to 100 days.

The rationale behind the observation of reduced spreads is that market makers compete against each other and set the spread to cover costs from inventory risk, adverse selection, and trading fees as explained in Stoll (1978) as well as in Glosten and Milgrom (1985). Since the XLP Program awards market makers with a fee rebate if they quote at the best bid and offer with minimum volume, market makers are enabled to further decrease spreads. Although market makers could register as Xetra Liquidity Providers prior to the start of the program in order to be eligible for the fee rebates, competition between registered market makers may not have been strong enough to significantly decrease spreads within the first ten days after the introduction of the XLP Program. For the longer observation windows, however, the results suggest that market makers at least partially pass over savings in transaction fees to market participants in the form of tighter spreads. The competition between market makers is further enhanced by the obligation of $20 \%$ presence time at the best bid and offer in order to qualify for the fee rebate. Also, the economic impact 
This table reports the fixed effects panel regression results for the XLP Program difference-in-differences coefficient ( $\beta_{2}$ from Equation 1). Dependent variables are Turnover in continuous trading, RelativeSpread, Depth(10), L1Volume, L2to10-Volume, and MinTickShare on Xetra and Euronext. The results are based on 13,400, 6,700 and 1,340 observations in case of the full sample for 100 days, 50 days, and ten days around the introduction of the XLP Program on October 4th, 2016 respectively. Results for the subsamples by market capitalization and percentage of quotes at minimum tick size are calculated for 100 days around the event. Controls for weekday-effects are included. We apply robust standard error estimations to correct for potential biases resulting from heteroscedasticity. Note: ${ }^{*} p<0.1,{ }^{* *} p<0.05,{ }^{* * *} p<0.01$.

\begin{tabular}{|c|c|c|c|c|c|c|}
\hline \multirow{4}{*}{ Full Sample } & \multicolumn{3}{|c|}{ Turnover } & \multicolumn{3}{|c|}{ RelativeSpread } \\
\hline & 100 days & 50 days & 10 days & 100 days & 50 days & 10 days \\
\hline & 2.224 & 1.620 & -4.384 & -0.420 & -0.197 & -0.102 \\
\hline & $\mathrm{t}=0.987$ & $\mathrm{t}=0.461$ & $\mathrm{t}=-0.979$ & $\mathrm{t}=-2.590^{* * *}$ & $\mathrm{t}=-2.236^{* *}$ & $\mathrm{t}=-1.481$ \\
\hline & Large (S1) & Medium (S2) & Small (S3) & Large (S1) & Medium (S2) & Small (S3) \\
\hline \multirow[t]{2}{*}{ Market Cap } & 2.995 & -1.847 & 5.139 & -0.068 & -0.560 & -0.648 \\
\hline & $\mathrm{t}=0.616$ & $\mathrm{t}=-0.656$ & $\mathrm{t}=1.530$ & $\mathrm{t}=-0.254$ & $\mathrm{t}=-3.328^{* * *}$ & $\mathrm{t}=-1.975^{* *}$ \\
\hline \multirow[t]{4}{*}{ MinTickShare } & 2.371 & 4.374 & 0.053 & -0.225 & -0.578 & -0.469 \\
\hline & $\mathrm{t}=0.585$ & $\mathrm{t}=1.137$ & $\mathrm{t}=0.015$ & $\mathrm{t}=-0.872$ & $\mathrm{t}=-2.453^{* *}$ & $\mathrm{t}=-1.437$ \\
\hline & & Depth(10) & & & L1-Volume & \\
\hline & 100 days & 50 days & 10 days & 100 days & 50 days & 10 days \\
\hline \multirow[t]{3}{*}{ Full Sample } & 1.497 & 1.189 & 1.437 & 0.179 & 0.194 & 0.203 \\
\hline & $\mathrm{t}=3.541^{* * *}$ & $\mathrm{t}=3.663^{* * *}$ & $\mathrm{t}=5.821^{* * *}$ & $\mathrm{t}=1.542$ & $\mathrm{t}=2.972^{* * *}$ & $\mathrm{t}=4.012^{* * *}$ \\
\hline & Large (S1) & Medium (S2) & Small (S3) & Large (S1) & Medium (S2) & Small (S3) \\
\hline \multirow[t]{2}{*}{ Market Cap } & 1.136 & 2.121 & 1.292 & 0.418 & 0.094 & 0.016 \\
\hline & $\mathrm{t}=1.194$ & $\mathrm{t}=3.342^{* * *}$ & $\mathrm{t}=3.061^{* * *}$ & $\mathrm{t}=1.454$ & $\mathrm{t}=0.792$ & $\mathrm{t}=0.189$ \\
\hline \multirow[t]{4}{*}{ MinTickShare } & 1.562 & 2.148 & 0.840 & 0.468 & 0.158 & -0.091 \\
\hline & $\mathrm{t}=1.737^{*}$ & $\mathrm{t}=3.087^{* * *}$ & $\mathrm{t}=1.683^{*}$ & $\mathrm{t}=1.747^{*}$ & $\mathrm{t}=0.951$ & $\mathrm{t}=-0.935$ \\
\hline & & L2to10-Volum & & & MinTickShare & \\
\hline & 100 days & 50 days & 10 days & 100 days & 50 days & 10 days \\
\hline \multirow[t]{3}{*}{ Full Sample } & 10.452 & 13.543 & 21.347 & 0.003 & 0.005 & -0.013 \\
\hline & $\mathrm{t}=0.530$ & $\mathrm{t}=1.441$ & $\mathrm{t}=2.969^{* * *}$ & $\mathrm{t}=0.118$ & $\mathrm{t}=0.259$ & $\mathrm{t}=-0.764$ \\
\hline & Large (S1) & Medium (S2) & Small (S3) & Large (S1) & Medium (S2) & Small (S3) \\
\hline \multirow[t]{2}{*}{ Market Cap } & 44.404 & -0.587 & -13.843 & 0.052 & 0.015 & -0.056 \\
\hline & $\mathrm{t}=1.022$ & $\mathrm{t}=-0.021$ & $\mathrm{t}=-0.607$ & $\mathrm{t}=1.143$ & $\mathrm{t}=0.363$ & $\mathrm{t}=-1.038$ \\
\hline \multirow[t]{2}{*}{ MinTickShare } & 55.083 & 2.742 & -27.281 & 0.031 & 0.046 & -0.063 \\
\hline & $\mathrm{t}=1.380$ & $\mathrm{t}=0.087$ & $\mathrm{t}=-1.025$ & $\mathrm{t}=0.719$ & $\mathrm{t}=1.123$ & $\mathrm{t}=-1.133$ \\
\hline
\end{tabular}

Table 5: Results of the DiD-regression for the single-market perspective. 
of the spread reduction is meaningful since the average pre-event spread of $4.93 \mathrm{bps}$ on Xetra (see Table 2) is reduced by 0.42 bps (8.5\%) due to the XLP Program in the observation window of 100 days. Moreover, as round-trip transaction fees for market participants with high volumes on Xetra amount to 0.72 bps (0.36 bps per executed order), a spread reduction of 0.42 bps indicates that market makers pass over at least $58 \%$ of their savings in fee rebates to market participants. ${ }^{8}$

Looking at the subsamples with respect to market capitalization and percentage of quotes at minimum tick size, the decrease in spreads is robust across all six groups. However, the DiD-coefficient is only significant for those DAX30 stocks with medium (S2) and small (S3) market capitalization or medium (S2) percentage of quotes at minimum tick size. A possible explanation for this observation could be the fact that stocks with high market capitalization are already very liquid which leaves less room for further improvements in liquidity. This also holds for stocks that often already trade at their minimum tick size in the pre-event period.

Besides improvements in relative spreads, the XLP Program also aims at increasing volumes at the top of the order book. Our results show that the liquidity provider program achieves this goal since both the order book depth (Depth(10)) as well as the euro volume at the top of the order book (L1-Volume) increase as suggested by positive DiD-coefficients which are robust across all observation windows and subsamples. The effect is significant for all different observation windows regarding order book depth and for the 50 days and ten days periods regarding volume top of the book. For the 100 days observation window, the increase in L1-Volume is tightly insignificant. The rationale behind the increase in order book depth and L1-Volume is that market makers need to fulfill minimum volume requirements of 5,000 euro in order to qualify for the fee rebates. Moreover, minimum presence time at the top of the book incentivizes liquidity providers to provide liquidity at the first order book level and to shift volumes on deeper order book levels back to the top more often. In this regard, the results for L2to10-Volume provide evidence that additional volume submitted to the top of the order book has not moved from deeper levels of the order book to the top but is indeed additional quoted volume on Xetra. Besides the short observation period of 10 days around the event, none of the parameters regarding these lower levels of the order book show significant effects and the results are not robust for different time periods and subsamples indicating that additional volume quoted at top of the order book cannot be explained by a shift of orders from deeper

8 Assuming orders submitted by Xetra Liquidity Providers are only executed passively. If Xetra Liquidity Providers also use liquidity taking orders (i.e. executable limit orders or market orders), which are not subject to this fee rebate, the percentage of savings passed over to market participants is even higher. 
order book levels. Also, the XLP program does not lead to a significant increase of liquidity at lower order book levels.

The increase in volume based liquidity measures is also meaningful from an economic perspective. Compared to the average pre-event order book depth of 1.08 million euro on Xetra, order book depth increases by 0.1497 million euro (13.9\%) due to the introduction of the XLP Program based on the 100 days observation window. For the L1-Volume, the increase resulting from the XLP Program amounts to 17,900 euro $(17.9 \%)$ compared to an average of 0.1 million euro prior to the event (see Table 2 and the respective DiD-coefficient in Table 5).

For the subsample analysis, the results for order book depth are comparable to the observations concerning relative spreads. Again, the increase in order book depth is significant for medium size and small DAX30 companies while being insignificant for the largest ten DAX30 stocks likely due to the already very high level of order book depth in those stocks. Regarding the minimum tick size subsamples, the DiDcoefficients are positive and significant for all three groups. While a large share of quotes at minimum tick size restricts the potential for liquidity improvement in terms of relative spreads, the possibility for liquidity providers to submit additional passive volume to the order book is not limited for all three minimum tick size groups. For the subsample analysis of L1-Volume, a significant effect can only be observed for stocks with a high percentage of quotes at minimum tick size (S1). Since further spread reductions below minimum tick size are not possible, additional volume at the top of the book accumulates. This observation is in line with studies analyzing an increase in minimum tick size (e.g., Griffith and Roseman, 2017).

As the analysis shows, the XLP Program successfully increases liquidity on the main market Xetra along different dimensions. Consequently, the market might gain additional order flow resulting in higher trading volumes. However, no significant changes can be observed in turnover during continuous trading after the introduction of the XLP Program. As a consequence, the improvement in liquidity does not lead to additional turnover on Xetra in absolute terms. This holds for all three different time intervals analyzed around the introduction of the XLP Program as well as all subsamples according to market capitalization and all subsamples according to percentage of quotes at minimum tick size.

Market operators introducing liquidity provider incentives aim at increasing their market share regarding aggregate turnover in the fragmented market environment. Moreover, single-market liquidity parameters can also be analyzed relative to the aggregate fragmented market liquidity. Table 6 reports the results for changes in market share and contribution of a single venue to the consolidated liquidity available to market participants. 
Regression Results: Contribution of the Main Market to Consolidated Turnover and Liquidity

This table reports the fixed effects panel regression results for the XLP Program difference-in-differences coefficient ( $\beta_{2}$ from Equation 1). Dependent variables are market share of turnover in continuous trading (MarketShare), relative spread (EBBOShare), Depth(10) (Depth(10)Share), and L1-Volume (L1 - VolumeShare) of Xetra and Euronext relative to the consolidated market. The results are based on 13,400, 6,700 and 1,340 observations in case of the full sample for 100 days, 50 days, and ten days around the introduction of the XLP Program on October 4th, 2016 respectively. Results for the subsamples by market capitalization and percentage of quotes at minimum tick size are calculated for 100 days around the event. Controls for weekday-effects are included. We apply robust standard error estimations to correct for potential biases resulting from heteroscedasticity. Note: ${ }^{*} p<0.1,{ }^{* *} p<0.05$, ${ }^{* * *} p<0.01$.

\begin{tabular}{|c|c|c|c|c|c|c|}
\hline & \multicolumn{3}{|c|}{ MarketShare } & \multicolumn{3}{|c|}{ EBBOShare } \\
\hline & 100 days & 50 days & 10 days & 100 days & 50 days & 10 days \\
\hline \multirow[t]{3}{*}{ Full Sample } & 0.061 & 0.034 & 0.012 & 0.057 & 0.027 & 0.002 \\
\hline & $\mathrm{t}=8.526^{* * *}$ & $\mathrm{t}=5.672^{* * *}$ & $\mathrm{t}=1.824^{*}$ & $\mathrm{t}=3.213^{* * *}$ & $\mathrm{t}=2.312^{* *}$ & $\mathrm{t}=0.283$ \\
\hline & Large (S1) & Medium (S2) & Small (S3) & Large (S1) & Medium (S2) & Small (S3) \\
\hline \multirow[t]{2}{*}{ Market Cap } & 0.050 & 0.063 & 0.071 & 0.054 & 0.050 & 0.067 \\
\hline & $\mathrm{t}=5.443^{* * *}$ & $\mathrm{t}=4.137^{* * *}$ & $\mathrm{t}=6.415^{* * *}$ & $\mathrm{t}=1.802^{*}$ & $\mathrm{t}=1.741^{*}$ & $\mathrm{t}=2.352^{* *}$ \\
\hline \multirow[t]{4}{*}{ MinTickShare } & 0.034 & 0.058 & 0.091 & 0.013 & 0.055 & 0.104 \\
\hline & $\mathrm{t}=3.267^{* * *}$ & $\mathrm{t}=6.904^{* * *}$ & $\mathrm{t}=6.694^{* * *}$ & $\mathrm{t}=0.510$ & $\mathrm{t}=2.060^{* *}$ & $\mathrm{t}=3.679^{* * *}$ \\
\hline & \multicolumn{3}{|c|}{ Depth(10)Share } & \multicolumn{3}{|c|}{ L1-VolumeShare } \\
\hline & 100 days & 50 days & 10 days & 100 days & 50 days & 10 days \\
\hline \multirow[t]{3}{*}{ Full Sample } & 0.034 & 0.037 & 0.018 & 0.093 & 0.071 & 0.026 \\
\hline & $\mathrm{t}=3.890^{* * *}$ & $\mathrm{t}=4.988^{* * *}$ & $\mathrm{t}=4.967^{* * *}$ & $\mathrm{t}=7.987^{* * *}$ & $\mathrm{t}=7.707^{* * *}$ & $\mathrm{t}=4.495^{* * *}$ \\
\hline & Large (S1) & Medium (S2) & Small (S3) & Large (S1) & Medium (S2) & Small (S3) \\
\hline \multirow[t]{2}{*}{ Market Cap } & 0.007 & 0.038 & 0.058 & 0.073 & 0.090 & 0.115 \\
\hline & $\mathrm{t}=0.596$ & $\mathrm{t}=2.757^{* * *}$ & $\mathrm{t}=3.899^{* * *}$ & $\mathrm{t}=3.691^{* * *}$ & $\mathrm{t}=4.655^{* * *}$ & $\mathrm{t}=6.166^{* * *}$ \\
\hline \multirow[t]{2}{*}{ MinTickShare } & 0.012 & 0.026 & 0.064 & 0.044 & 0.090 & 0.143 \\
\hline & $\mathrm{t}=0.857$ & $\mathrm{t}=1.854^{*}$ & $\mathrm{t}=4.177^{* * *}$ & $\mathrm{t}=2.612^{* * *}$ & $\mathrm{t}=5.410^{* * *}$ & $\mathrm{t}=8.062^{* * *}$ \\
\hline
\end{tabular}

Table 6: Results of the DiD-regression for the proportional contribution of the main market to consolidated turnover and liquidity. 
The picture of the contributions of the single market to the consolidated market supports the success of the XLP Program further. Across all liquidity and turnover contribution measures, the contribution of Xetra to aggregate turnover and liquidity increases significantly. After the introduction of the market maker scheme, the market share of Xetra regarding turnover increases significantly. This result is robust across all observation periods and subsamples. Moreover, the magnitude of the increase is higher the longer the observation period, showing that the increase in market share goes hand in hand with decreasing relative spreads on Xetra. The difference in significant effects between absolute turnover and turnover market share of Xetra shows that total turnover in DAX30 stocks did not increase due to the XLP Program but was redistributed among the four analyzed venues Xetra, BS, CHI, and TQ towards the main market Xetra. Specifically, the results of the panel regression show that the market share of Xetra increases by 6.1 percentage points due to the XLP Program. Based on the average pre-event market share of Xetra in turnover of DAX30 stocks of $52 \%$, this equals an increase of $11.7 \%$.

Similar to the relative spread on Xetra, the share of Xetra showing the best available bid and offer of the consolidated market (EBBOShare) is also positive across all observation periods and subsamples and becomes significant from the 50 days observation period onwards. In addition, the positive effect again can be traced back to small and medium sized DAX30 companies and to those stocks that rarely traded at their minimum tick size in the pre-event period. Moreover, the magnitude of the effect increases with the length of the observation period which again supports the hypothesis that competition between market makers needs some time to evolve after the introduction of the liquidity provider program. Within the 100 days observation window, the share of Xetra offering the best available best bid and offer in the consolidated order book increases from $52 \%$ by 5.7 percentage points $(11 \%)$ due to the XLP Program.

Also, Xetra's contribution to the volume based liquidity measures of the consolidated order book increases significantly which is robust and consistent across all observation windows and subsamples. The contribution of Xetra to the consolidated order book depth measured by Depth(10) increases by 3.4 percentage points $(5.7 \%)$ compared to an average pre-event share in consolidated order book depth of $60 \%$. The rise in contribution to L1-Volume attributable to the liquidity provider program on Xetra amounts to 9.3 percentage points (24.5\%) based on a pre-event share of Xetra in L1-Volume of $38 \%$.

The DiD-analysis reveals that a single-market liquidity provider program in a fragmented market helps the respective market to increase its liquidity both in absolute terms as well as compared to the liquidity offered by other markets. Moreover, the market maker program supports the market operator to gain market shares from 
competing venues while no effect on turnover in absolute terms can be attributed to the program.

\subsection{The Effect of the XLP Program on Liquidity and Turnover in the Consolidated Market}

Having analyzed the effects of the XLP Program on Xetra, the focus of this subsection is on possible changes in aggregate liquidity and turnover in the multi-market environment for trading DAX30 stocks. This consolidated view of the fragmented market is relevant for market participants that can easily access different liquidity pools in the multi-market setting using algorithms and/or smart order routing systems. Consequently, the consolidated multi-market perspective reveals whether the single-market liquidity provider program affects liquidity and turnover in the fragmented market as a whole.

We repeat the DiD-analysis using trading in CAC40 stocks as a control group, however, instead of analyzing turnover and liquidity measures of the respective main market, we now focus on possible changes in consolidated liquidity and turnover. Table 7 depicts the panel regression results of the analyzed parameters considering the consolidated market.

From the perspective of the market participants having access to the liquidity pools of multiple markets, the effect of the XLP Program on consolidated liquidity and turnover is highly relevant. Particularly, the consolidated market view reveals whether the program has an effect on the market as a whole or whether it rather leads to a redistribution of liquidity among competing venues making it more attractive for market participants to trade on the main venue because of tighter spreads and more available volume at the top of the order book. The DiD panel regression results of the relative spread for the consolidated market reveal that - in contrast to the main market - there is no significant effect for all observation periods of 100 , 50 , and ten trading days. The same results apply for the subsamples, differentiated by market capitalization and percentage of quotes at minimum tick size for the 100 days period. Since there is no incentive to provide tighter spreads on the alternative venues, the effect of the main market is too weak to result in a significant change in the consolidated market.

We also analyze how the single-market liquidity provider program affects Depth(10) and L1-Volume in the consolidated market. On the main market, there are significant upside effects for both order book depth and L1-Volume due to the requirements set by the market maker scheme. A significant increase in order book depth and L1-Volume on the main venue, which has an average pre-event share of $37.66 \%$ in 


\begin{tabular}{|c|c|c|c|c|c|c|}
\hline \multicolumn{7}{|c|}{ Regression Results: Multi-Market Perspective } \\
\hline \multicolumn{7}{|c|}{$\begin{array}{l}\text { This table reports the fixed effects panel regression results for the XLP Program difference-in-differences coefficient } \\
\text { ( } \beta_{2} \text { from Equation 1). Dependent variables are Turnover in continuous trading, RelativeSpread, Depth(10), and } \\
L 1-\text { Volume in the consolidated markets for trading DAX30 and CAC40 stocks. The results are based on } 13,400 \text {, } \\
6,700 \text { and } 1,340 \text { observations in case of the full sample for } 100 \text { days, } 50 \text { days, and ten days around the introduction } \\
\text { of the XLP Program on October } 4 \text { th, } 2016 \text { respectively. Results for the subsamples by market capitalization and } \\
\text { percentage of quotes at minimum tick size are calculated for } 100 \text { days around the event. Controls for weekday- } \\
\text { effects are included. We apply robust standard error estimations to correct for potential biases resulting from } \\
\text { heteroscedasticity. Note: }{ }^{*} p<0.1,{ }^{* *} p<0.05,{ }^{* * *} p<0.01 \text {. }\end{array}$} \\
\hline \multirow{4}{*}{ Full Sample } & \multicolumn{3}{|c|}{ Turnover } & \multicolumn{3}{|c|}{ RelativeSpread } \\
\hline & 100 days & 50 days & 10 days & 100 days & 50 days & 10 days \\
\hline & $\begin{array}{c}-10.594 \\
\mathrm{t}=-2.410^{* *}\end{array}$ & $\begin{array}{c}-5.784 \\
\mathrm{t}=-1.034\end{array}$ & $\begin{array}{c}-11.164 \\
\mathrm{t}=-1.490\end{array}$ & $\begin{array}{c}-0.089 \\
\mathrm{t}=-0.631\end{array}$ & $\begin{array}{c}0.040 \\
\mathrm{t}=0.434\end{array}$ & $\begin{array}{c}-0.071 \\
\mathrm{t}=-1.139\end{array}$ \\
\hline & Large (S1) & Medium (S2) & Small (S3) & Large (S1) & Medium (S2) & Small (S3) \\
\hline Market Cap & $\begin{array}{c}-15.237 \\
\mathrm{t}=-1.503\end{array}$ & $\begin{array}{c}-14.822 \\
\mathrm{t}=-2.512^{* *}\end{array}$ & $\begin{array}{c}-2.097 \\
\mathrm{t}=-0.435\end{array}$ & $\begin{array}{c}0.090 \\
\mathrm{t}=0.378\end{array}$ & $\begin{array}{c}-0.166 \\
\mathrm{t}=-0.857\end{array}$ & $\begin{array}{c}-0.203 \\
\mathrm{t}=-0.764\end{array}$ \\
\hline \multirow[t]{3}{*}{ MinTickShare } & $\begin{array}{c}-7.385 \\
\mathrm{t}=-1.172\end{array}$ & $\begin{array}{c}-12.231 \\
\mathrm{t}=-1.311\end{array}$ & $\begin{array}{c}-12.477 \\
\mathrm{t}=-1.999^{* *}\end{array}$ & $\begin{array}{c}-0.084 \\
\mathrm{t}=-0.373\end{array}$ & $\begin{array}{c}-0.199 \\
\mathrm{t}=-0.991\end{array}$ & $\begin{array}{c}0.007 \\
\mathrm{t}=0.024\end{array}$ \\
\hline & & Depth(10) & & & L1-Volume & \\
\hline & 100 days & 50 days & 10 days & 100 days & 50 days & 10 days \\
\hline \multirow[t]{2}{*}{ Full Sample } & $\begin{aligned} & 1.332 \\
\mathrm{t}= & 1.844^{*}\end{aligned}$ & $\begin{array}{c}0.533 \\
\mathrm{t}=0.907\end{array}$ & $\begin{aligned} & 1.553 \\
\mathrm{t}= & 3.945^{* * *}\end{aligned}$ & $\begin{array}{c}0.122 \\
\mathrm{t}=0.668\end{array}$ & $\begin{array}{c}0.081 \\
\mathrm{t}=0.815\end{array}$ & $\begin{array}{c}0.169 \\
\mathrm{t}=2.540^{* *}\end{array}$ \\
\hline & Large (S1) & Medium (S2) & Small (S3) & Large (S1) & Medium (S2) & Small (S3) \\
\hline Market Cap & $\begin{array}{c}0.843 \\
\mathrm{t}=0.509\end{array}$ & $\begin{array}{c}1.957 \\
\mathrm{t}=1.704^{*}\end{array}$ & $\begin{array}{c}1.249 \\
\mathrm{t}=1.821^{*}\end{array}$ & $\begin{array}{c}0.542 \\
\mathrm{t}=1.208\end{array}$ & $\begin{array}{c}-0.072 \\
\mathrm{t}=-0.390\end{array}$ & $\begin{array}{c}-0.126 \\
t=-0.933\end{array}$ \\
\hline MinTickShare & $\begin{aligned} & 2.063 \\
& \mathrm{t}=1.695^{*}\end{aligned}$ & $\begin{array}{c}1.951 \\
\mathrm{t}=1.226\end{array}$ & $\begin{array}{c}0.031 \\
\mathrm{t}=0.037\end{array}$ & $\begin{array}{c}0.560 \\
\mathrm{t}=1.269\end{array}$ & $\begin{array}{c}0.023 \\
\mathrm{t}=0.093\end{array}$ & $\begin{array}{c}-0.226 \\
\mathrm{t}=-1.601\end{array}$ \\
\hline
\end{tabular}

Table 7: Results of the DiD-regression for the multi-market perspective. 
L1-Volume and $60.03 \%$ in Depth(10), may have an effect on the consolidated market as well. But this can only happen if the quoted volume on the main market is additional to the existing consolidated quoted volume and not only a shift of quoted volume to the main venue. For the ten days period of the full sample, order book depth and L1-Volume show a significant positive effect. For the L1-Volume, the positive effect is only short-term and vanishes in the 50 and 100 days periods. Regarding order book depth, the effect is not significant for the 50 days period, but there is again a positive significant effect for the 100 days period on the ten percent level. Consequently, the results show weak positive effects on consolidated liquidity in terms of order book depth and L1-Volume. However, the effects are not robust across the observation windows and the different subsamples according to market capitalization and percentage of quotes at minimum tick size.

For the aggregate turnover, the consolidated market even shows significant negative effects for the 100 days period instead of a possible increase in turnover due to the introduction of the XLP Program. However, the effect for the other observation periods and subsamples is mostly insignificant. Consequently, no additional turnover is generated in the market as a whole, leading to the conclusion that any gains of Xetra, on which the liquidity provider program is implemented, are at the expense of competing alternative venues. In summary, the analysis of the consolidated market perspective reveals that there is no benefit of a single-market liquidity provider program for the consolidated market. There is no significant change in the relative spread of the consolidated order book as well as for order book depth and L1-Volume based on most observation periods. Thus, an increase in aggregate liquidity of the consolidated market due to the XLP Program is not observable.

\section{Discussion}

Our analysis shows that single-market liquidity provider programs such as the XLP Program on Xetra indeed increase liquidity on the respective market. The results demonstrate that relative spreads decrease while order book depth and volume at the best bid and offer increase due to the liquidity provider program. Regarding relative spreads, the results are particularly strong for smaller blue-chip companies and those stocks that seldom trade at their minimum tick size, which leaves more room for improvements due to the liquidity provider incentives. This increase in absolute liquidity on the single market also leads to a higher contribution of the respective venue to the consolidated liquidity in the fragmented market environment. Consequently, the venue introducing the liquidity provider incentives increases its share in offering the available best bid and offer as well as the share in consolidated order book depth and consolidated volume at the top of the order book. The 
higher liquidity level on the single market also attracts additional trading interest leading to gains in market share in terms of turnover at the expense of competing venues. Besides the positive effects for liquidity on the introducing venue, we do not find any evidence that liquidity providers adjust their quoting behavior during each month expecting to have already fulfilled their monthly requirements. This indicates that the examined liquidity provider scheme provides stable quoting incentives for registered liquidity providers over each month.

However, while there is a strong effect on liquidity and market share of the singlemarket, no significant effect of the liquidity provider program can be observed for aggregate liquidity and turnover in the consolidated market. The results only show a small positive effect on consolidated order book depth which is nonetheless not robust across all observation periods and subsamples. Consequently, our analysis supports that single-market liquidity provider incentives, that are based on parameters of that market, e.g., a contribution to the respective market's best bid and offer volume, lead to a redistribution of liquidity and turnover but do not attract additional turnover and liquidity to the consolidated market as a whole. In case the target is the improvement of consolidated liquidity, incentives should be designed based on consolidated parameters, e.g., a contribution to the EBBO. This may grow the pie of aggregate liquidity and turnover instead of just redistributing it.

The results regarding spreads on the single market are in line with the theoretical predictions of Colliard and Foucault (2012) showing that reduced make fees may lead to decreased spreads. Our results regarding turnover for the single market, however, differ from the results of Foucault et al. (2013), who argue that a reduction in make fees can increase the trading rate. Of course, adjustments in make and take fees for above mentioned models account for all market participants, whereas the fee reductions of the XLP Program only account for specific registered market makers. Besides these studies and other research analyzing the effects of liquidity provider incentives and changes in markets' pricing schemes, we also contribute to studies investigating the effect of liquidity on turnover. Relevant literature reveals partly inconsistent results for the effect of improved liquidity on trading volume. Moreover, it remains unclear whether additional volume increases liquidity (Pagano, 1989), increased liquidity attracts additional volume (Goss and Avsar, 2002) or whether any relation between liquidity and volume exists at all (Johnson, 2008). Our analysis contributes to these considerations highlighting that increased liquidity due to liquidity provider incentives leads to a higher market share of the respective venue in terms of turnover. However, our findings also suggest that any observed improvements are rather the result of a redistribution among markets than additional liquidity and turnover associated with a real welfare aspect. 
The results of our analysis are highly relevant for market participants and market operators alike. On the one hand, they support market operators when deciding about means to increase liquidity and market share. Specifically, market operators can use the results of our study to assess how the introduction of a liquidity provider incentive program might affect both liquidity and turnover of the market itself as well as relative to the consolidated turnover and liquidity in fragmented market environments. On the other hand, market participants also benefit from our results in their order routing decisions after the application of single-market liquidity provider incentives.

There are some limitations connected to our study. First, our analysis is based on one specific liquidity provider incentive program, i.e., the XLP Program on Xetra. Consequently, the results may not be completely generalizable for other programs. However, the requirements for market participants to qualify for the fee rebates, which demand a minimum presence time at the top of the order book with sufficient volume, are quite standard for market maker schemes so that the results of our analysis should be transferable most other programs (Colliard and Foucault, 2012; Dosanjh, 2013). Also, the ordering of order book snapshots from different venues in order to calculate a consolidated order book may suffer from inaccurate time stamps during times of high activity. However, our approach is the most detailed way to construct a consolidated order book and the small share of crossed order book situation shows that the procedure works well. Last, we rely on a differencein-differences approach to exclude any confounding effects using the stocks of the CAC40 index as control group. Although DAX30 and CAC40 are highly correlated, there might still be other effects than the liquidity provider program that only affect the German stocks and not the control group of French stocks or the other way around. Nevertheless, this approach appears to be the most accurate in order to avoid confounding effects and the analysis shows that the parameters taken into account are closely related for the DAX30 and the CAC40 index.

\section{Conclusion}

We study the introduction of a single-market liquidity provider program in a fragmented market environment. Specifically, we analyze the effects of the XLP Program on liquidity and turnover of the introducing market itself and the fragmented market as a whole. In order to assess the effects of the market maker scheme on liquidity and turnover for the market that introduces the program as well as for the fragmented market as a whole, we analyze both the perspective of the single market as well as the perspective of market participants interested in consolidated liquidity since they can access different liquidity pools, e.g., by using smart order routing systems. 
Our results show strong support for the effectiveness of liquidity provider incentives for the market that introduces them. This is especially relevant for stocks beyond the most-liquid stocks and thus, in the case of the liquidity provider program investigated in our analysis, a further extension of the program beyond DAX30 stocks could be considered by the market operator.

However, no gains for aggregate liquidity and turnover can be observed. Rather than increasing aggregate liquidity leading to additional trading interest due to lower transaction costs, market participants seem to redistribute liquidity provision and trading activity to the market offering fee rebates for market makers. As a consequence, a single-market liquidity provider program, which only links the incentive to quality parameters on that market, increases the respective market's liquidity and market share at the expense of competing venues and does not lead to welfare gains in a fragmented market environment. Therefore, linking incentives to quality parameters referring to the consolidated market, i.e., an incentive for quotation at the consolidated spread (EBBO), will likely not only increase the market share of the incentivizing market but will likely increase aggregate liquidity and turnover in the fragmented market as a whole. 


\section{References}

Anand, Amber and Kumar Venkataraman (2013). "Should Exchanges Impose Market Maker Obligations." In: Working Paper.

Battalio, Robert and Craig W. Holden (2001). "A Simple Model of Payment for Order Flow, Internalization, and Total Trading Cost." In: Journal of Financial Markets 4.1, pp. 33-71.

Battalio, Robert, Robert Jennings, and Jamie Selway (2001). "The Relationship Among Market-Making Revenue, Payment for Order Flow, and Trading Costs for Market Orders." In: Journal of Financial Services Research 19.1, pp. 39-56.

Battalio, Robert and Paul Schultz (2011). "Regulatory Uncertainty and Market Liquidity: The 2008 Short Sale Ban's Impact on Equity Option Markets." In: The Journal of Finance 66.6, pp. 2013-2053.

Bessembinder, Hendrik, Jia Hao, and Michael Lemmon (2011). "Why Designate Market Makers? Affirmative Obligations and Market Quality." In: Working Paper.

Cao, Charles, Hyuk Choe, and Frank Hatheway (1997). "Does the Specialist Matter? Differential Execution Costs and Intersecurity Subsidization on the New York Stock Exchange." In: The Journal of Finance 52.4, pp. 1614-1640.

Colliard, Jean-Edouard and Thierry Foucault (2012). "Trading Fees and Efficiency in Limit Order Markets." In: Review of Financial Studies 25.11, pp. 3389-3421.

Degryse, Hans, Frank de Jong, and Vincent van Kervel (2015). "The Impact of Dark Trading and Visible Fragmentation on Market Quality." In: Review of Finance 19.4, pp. 1587-1622.

Deutsche Boerse Group (2016). Xetra Circular 069/16: Introduction of a Xetra Liquidity Provider Pilot-Programme for DAX30 instruments. URL: http: / / www . xetra . com/blob/2692370/59e557691bab29c0b2b5b5d0951666a8/data/069_ 16e.pdf (visited on 02/20/2017).

- (2017). Xetra Circular 014/17: Amendment to the Price List for the Utilization of the Exchange EDP of FWB Frankfurt Stock Exchange and of the EDP XONTRO - Introduction of the Xetra Liquidity Provider Programme. URL: http: //www . xetra . com/blob/2918510/c2913ff51bd810faf9ff7005b9c16a22/data/014_ 17e.pdf (visited on 02/20/2017).

Dosanjh, Jagjeev S. (2013). "Market Maker Incentives and Market Efficiency: Evidence from the Australian ETF Market." In: Working Paper.

Fidessa (2017). Fidessa Fragmentation Index: Making Sense of Global Fragmentation. URL: http://fragmentation.fidessa.com/ (visited on 03/15/2017).

Foucault, Thierry, Ohad Kadan, and Eugene Kandel (2013). "Liquidity Cycles and Make/Take Fees in Electronic Markets." In: The Journal of Finance 68.1, pp. 299-341. 
Foucault, Thierry and Albert J. Menkveld (2008). "Competition for Order Flow and Smart Order Routing Systems." In: The Journal of Finance 63.1, pp. 119-158. Glosten, Lawrence R. and Paul R. Milgrom (1985). "Bid, Ask and Transaction Prices in a Specialist Market with Heterogeneously Informed Traders." In: Journal of Financial Economics 14.1, pp. 71-100.

Gomber, Peter, Satchit Sagade, Erik Theissen, Moritz Christian Weber, and Christian Westheide (2017). "Competition Between Equity Markets: A Review of the Consolidation Versus Fragmentation Debate." In: Journal of Economic Surveys 31.3, pp. $792-814$.

Goss, Barry A. and S. Gulay Avsar (2002). "Concentration and Liquidity in Mature Markets: Evidence from the US Dollar/Yen Futures Market." In: Australian Economic Papers 41.4, pp. 577-591.

Gresse, Carole (2017). "Effects of Lit and Dark Market Fragmentation on Liquidity." In: Journal of Financial Markets 35, pp. 1-20.

Griffith, Todd and Brian Roseman (2017). "Making Cents of Tick Sizes: An Investigation of the 2016 US SEC Tick Size Pilot." In: Working Paper.

Hendershott, Terrence, Charles M. Jones, and Albert J. Menkveld (2011). "Does Algorithmic Trading Improve Liquidity?" In: The Journal of Finance 66.1, pp. 133 .

Imbens, Guido W. and Jeffrey M. Wooldridge (2009). "Recent Developments in the Econometrics of Program Evaluation." In: Journal of Economic Literature 47.1, pp. 5-86.

Johnson, Timothy C. (2008). "Volume, Liquidity, and Liquidity Risk." In: Journal of Financial Economics 87.2, pp. 388-417.

Malinova, Katya and Andreas Park (2015). "Subsidizing Liquidity: The Impact of Make/Take Fees on Market Quality." In: The Journal of Finance 70.2, pp. 509536.

O'Hara, Maureen and Mao Ye (2011). "Is Market Fragmentation Harming Market Quality?" In: Journal of Financial Economics 100.3, pp. 459-474.

Pagano, Marco (1989). "Trading Volume and Asset Liquidity." In: Quarterly Journal of Economics 104.2, pp. 255-274.

Panayi, Efstathios, Gareth W. Peters, Jon Danielsson, and Jean-Pierre Zigrand (2018). "Designating Market Maker Behaviour in Limit Order Book Markets." In: Econometrics and Statistics 5, pp. 20-44.

Parlour, Christine A. and Uday Rajan (2003). "Payment for Order Flow." In: Journal of Financial Economics 68.3, pp. 379-411.

Stoll, Hans R. (1978). "The Supply of Dealer Services in Securities Markets." In: The Journal of Finance 33.4, pp. 1133-1151. 
Venkataraman, Kumar and Andrew C. Waisburd (2007). "The Value of the Designated Market Maker." In: Journal of Financial and Quantitative Analysis 42.3, pp. $735-758$.

Wooldridge, Jeffrey M. (2002). Econometric Analysis of Cross Section and Panel Data. Cambridge, MA: MIT Press. 


\section{Appendix}

\begin{tabular}{|c|c|c|c|c|c|c|}
\hline \multicolumn{7}{|c|}{ Correlation of Selected European Stock Indices } \\
\hline \multicolumn{7}{|c|}{$\begin{array}{l}\text { This table reports closing price and turnover correlation of major European } \\
\text { stock indices during our observation period from May 13th, } 2016 \text { to February } \\
\text { 21st, } 2017 \text {. }\end{array}$} \\
\hline \multicolumn{7}{|c|}{ Closing Price Correlation } \\
\hline & DAX30 & $\mathrm{CAC} 40$ & MDAX & IBEX35 & FTSE100 & FTSE MIB \\
\hline DAX30 & 1.000 & 0.975 & 0.929 & 0.899 & 0.858 & 0.823 \\
\hline CAC40 & & 1.000 & 0.875 & 0.837 & 0.847 & 0.737 \\
\hline MDAX & & & 1.000 & 0.936 & 0.791 & 0.893 \\
\hline IBEX35 & & & & 1.000 & 0.688 & 0.902 \\
\hline FTSE100 & & & & & 1.000 & 0.504 \\
\hline FTSE MIB & & & & & & 1.000 \\
\hline \multicolumn{7}{|c|}{ Turnover Correlation of Index Consitutents } \\
\hline & DAX30 & CAC40 & MDAX & IBEX35 & FTSE100 & FTSE MIB \\
\hline DAX30 & 1.000 & 0.895 & 0.802 & 0.853 & 0.815 & 0.779 \\
\hline CAC40 & & 1.000 & 0.781 & 0.722 & 0.732 & 0.635 \\
\hline MDAX & & & 1.000 & 0.905 & 0.879 & 0.827 \\
\hline IBEX35 & & & & 1.000 & 0.819 & 0.816 \\
\hline FTSE100 & & & & & 1.000 & 0.754 \\
\hline FTSE MIB & & & & & & 1.000 \\
\hline
\end{tabular}

Table A.1: Correlation of the German DAX30 index with selected European stock indices.

\begin{tabular}{ccc}
\hline \hline \multicolumn{3}{c}{ Tick Size Table for Xetra and Euronext } \\
\hline This table shows the applicable minimum tick size for DAX30 stocks traded \\
on Xetra and CAC40 stocks traded on Euronext during our observation period \\
from May 13th, 2016 to February 21st, 2017. During this period and prior to \\
MiFID II, both venues applied Table 4 of the Federation of European Securities \\
Exchanges (FESE) tick size tables (http://www.fese.eu/images/documents/ \\
UPDATED_FESE_TICK_SIZE_TABLES_AS_OF_OCT_2012.pdf). \\
\hline \hline Lower Price Limit (in euro) & Upper Price Limit (in euro) & Tick Size (in euro) \\
0 & 9.999 & 0.001 \\
10 & 49.995 & 0.005 \\
50 & 99.990 & 0.010 \\
100 & $\infty$ & 0.050 \\
\hline
\end{tabular}

Table A.2: Applicable tick size table for Xetra and Euronext during our observation period. 
Analyzed Liquidity and Turnover Parameters

This table includes all analyzed liquidity and turnover parameters as well as their symbols, descriptions, and calculations.

\begin{tabular}{|c|c|c|c|}
\hline \multicolumn{4}{|c|}{ Single- and Multi-Market Perspective } \\
\hline Name & Symbol & Description & Calculation \\
\hline Quoted relative spread & RelativeSpread & $\begin{array}{l}\text { Difference between best ask } \\
\text { and best bid price divided by } \\
\text { the midpoint }\end{array}$ & $\frac{\text { BestAsk }- \text { BestBid }}{0.5(\text { BestAsk }+ \text { BestBid })}$ \\
\hline Level 1 Volume & L1-Volume & $\begin{array}{l}\text { Euro volume available at the } \\
\text { best bid and offer }\end{array}$ & $\begin{array}{l}\text { Limit }_{1}^{\text {Ask }} \cdot \text { Quantity }_{1}^{\text {Ask }} \\
+ \text { Limit }_{1}^{\text {Bid }} \cdot \text { Quantity }_{1}^{\text {Bid }}\end{array}$ \\
\hline Level 2 to 10 Volume & L2to10-Volume & $\begin{array}{l}\text { Euro volume available be- } \\
\text { neath the best bid and offer } \\
\text { at the order book levels two } \\
\text { to ten }\end{array}$ & $\begin{array}{l}\sum_{i=2}^{10}\left(\text { Limit }_{i}^{A s k} \cdot \text { Quantity }_{i}^{\text {Ask }}\right. \\
\left.+ \text { Limit }_{i}^{\text {Bid }} \cdot \text { Quantity }_{i}^{\text {Bid }}\right) \\
i=\text { order book level }\end{array}$ \\
\hline Order book depth & $\operatorname{Depth}(10)$ & $\begin{array}{l}\text { Depth }(\mathrm{X}) \text { measures the or- } \\
\text { der book volume available } \mathrm{X} \\
\text { basis points around the mid- } \\
\text { point }\end{array}$ & See Equation 2 beneath the table \\
\hline Turnover & Turnover & $\begin{array}{l}\text { Total euro trading volume } \\
\text { without auction volumes } \\
\text { during continuous trading }\end{array}$ & Price $^{\text {Trade }} \cdot$ Quantity ${ }^{\text {Trade }}$ \\
\hline Share at minimum tick size & MinTickShare & $\begin{array}{l}\text { Share of quotes at minimum } \\
\text { tick size relative to all quotes }\end{array}$ & $\frac{\text { Number of quotes at minimum tick }}{\text { Number of all quotes }}$ \\
\hline \multicolumn{4}{|c|}{ Contribution of the Main Market to the Consolidated Market } \\
\hline Name & Symbol & Description & Calculation \\
\hline Market Share & MarketShare & $\begin{array}{l}\text { Contribution of the main } \\
\text { market to consolidated } \\
\text { turnover }\end{array}$ & $\frac{\text { Turnover } \operatorname{main}}{\sum_{j=1}^{4} \text { Turnover }}, j=$ trading venue \\
\hline EBBO Share & EBBOShare & $\begin{array}{l}\text { Contribution of the main } \\
\text { market to the consolidated } \\
\text { best bid and offer }\end{array}$ & $\begin{array}{l}\text { Percentage of main market quotes } \\
\text { that equal the EBBO }\end{array}$ \\
\hline Share in order book depth & Depth(10)Share & $\begin{array}{l}\text { Contribution of the main } \\
\text { market to consolidated order } \\
\text { book depth }\end{array}$ & $\frac{\operatorname{Depth}(10)_{\operatorname{main}}}{\sum_{j=1}^{4} \operatorname{Depth}(10)}, j=$ trading venue \\
\hline Share in Level 1 Volume & L1-VolumeShare & $\begin{array}{l}\text { Contribution of the main } \\
\text { market to consolidated level } \\
1 \text { volume }\end{array}$ & $\frac{L 1-\text { Volume }_{\text {main }}}{\sum_{j=1}^{4} \text { L1-Volume }}, j=$ trading venue \\
\hline
\end{tabular}

Table A.3: Analyzed liquidity and turnover parameters.

Calculation of Depth(X) (see Degryse et al., 2015):

$$
\begin{aligned}
\operatorname{DepthAsk}(X) & =\sum_{i=1}^{I} \operatorname{Price}_{i}^{\text {Ask }} \cdot \text { Quantity }_{i}^{\text {Ask }} \cdot \mathbb{1}_{\left\{\text {Price }_{i}^{A s k}<M \cdot(1+X)\right\}}, \\
\operatorname{DepthBid}(X) & =\sum_{i=1}^{I} \operatorname{Price}_{i}^{\text {Bid }} \cdot \operatorname{Quantity}_{i}^{\text {Bid }} \cdot \mathbb{1}_{\left\{\operatorname{Price}_{i}^{\text {Bid }}>M \cdot(1-X)\right\}}, \\
\operatorname{Depth}(X) & =\operatorname{DepthAsk}(X)+\operatorname{DepthBid}(X)
\end{aligned}
$$

where $M=\frac{\text { Price }_{i}^{A s k}+\text { Price }_{i}^{B i d}}{2}$ 

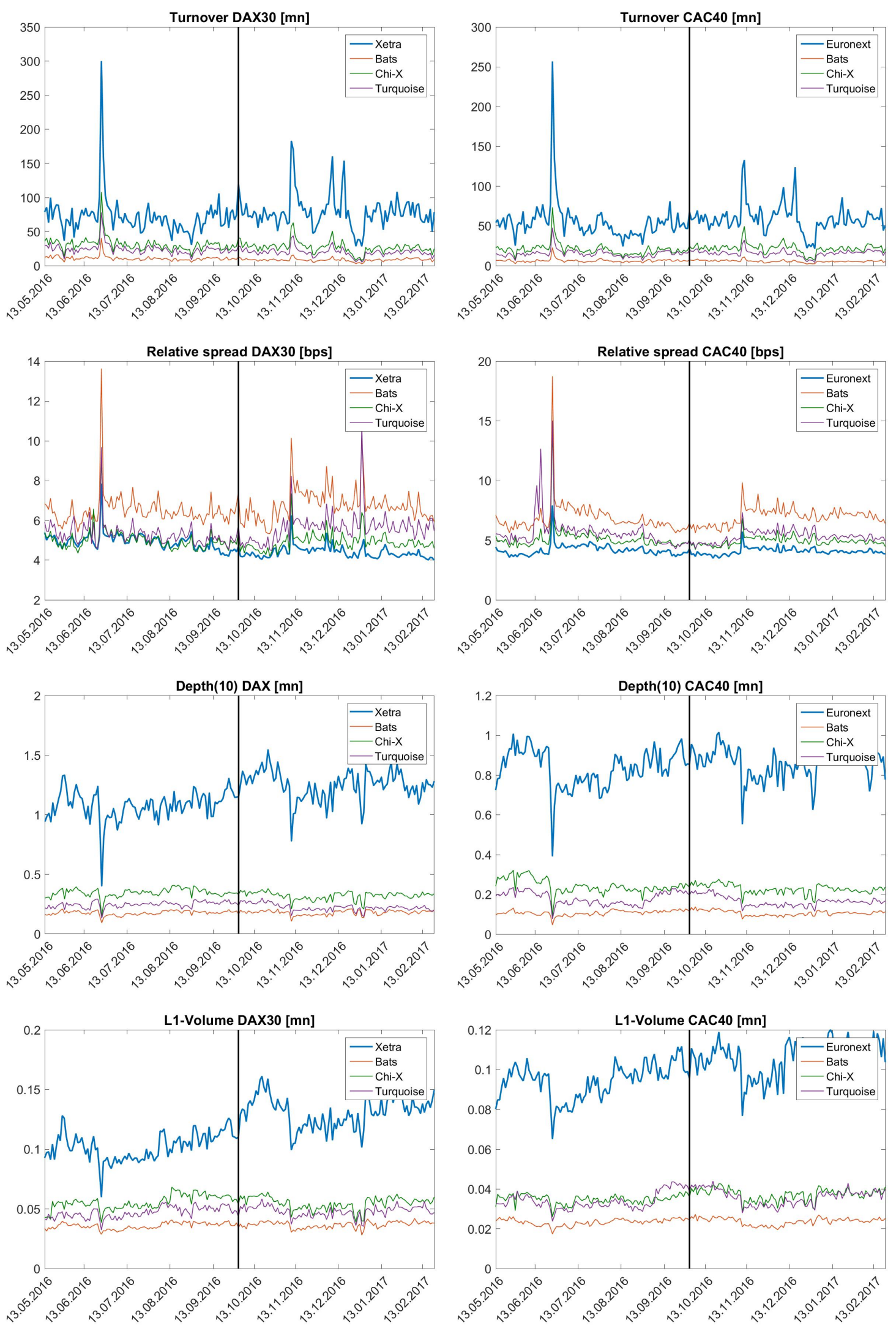

Figure A.1: Liquidity and turnover parameters for each stock index and venue. 


\begin{tabular}{|c|c|c|c|c|c|}
\hline \multicolumn{6}{|c|}{ Changes in Liquidity and Turnover of the Main Venue } \\
\hline \multicolumn{6}{|c|}{$\begin{array}{l}\text { This table reports the analyzed turnover and liquidity measures of the main } \\
\text { markets Xetra and Euronext averaged across } 50 \text { days before and } 50 \text { days } \\
\text { after the introduction of the XLP Program. Turnover, L1-Volume, L2to10- } \\
\text { Volume, and Depth(10) are reported in millions, relative spread is denotec } \\
\text { in basis points, and MinTickShare is shown in percent. }\end{array}$} \\
\hline & & Pre & Post & \%Change & DiD \\
\hline \multirow{2}{*}{ Turnover } & Xetra & 65.98 & 82.52 & $25.06 \%$ & \multirow{2}{*}{$-6.02 \%$} \\
\hline & Euronext & 48.10 & 63.05 & $31.07 \%$ & \\
\hline \multirow{2}{*}{ Relative Spread } & Xetra & 4.74 & 4.49 & $-5.40 \%$ & \multirow{2}{*}{$-3.95 \%$} \\
\hline & Euronext & 4.12 & 4.06 & $-1.45 \%$ & \\
\hline \multirow{2}{*}{$\operatorname{Depth}(10)$} & Xetra & 1.10 & 1.24 & $11.94 \%$ & \multirow{2}{*}{$10.42 \%$} \\
\hline & Euronext & 0.84 & 0.85 & $1.52 \%$ & \\
\hline \multirow{2}{*}{ L1-Volume } & Xetra & 0.11 & 0.13 & $20.90 \%$ & \multirow{2}{*}{$17.96 \%$} \\
\hline & Euronext & 0.10 & 0.10 & $2.95 \%$ & \\
\hline \multirow{2}{*}{ L2to10-Volume } & Xetra & 2.85 & 3.08 & $8.15 \%$ & \multirow{2}{*}{$2.79 \%$} \\
\hline & Euronext & 1.80 & 1.90 & $5.37 \%$ & \\
\hline \multirow{2}{*}{ MinTickShare } & Xetra & 29.73 & 32.72 & $10.04 \%$ & \multirow{2}{*}{$3.14 \%$} \\
\hline & Euronext & 35.80 & 38.27 & $6.90 \%$ & \\
\hline
\end{tabular}

Table A.4: Changes in liquidity and turnover of the main venue 50 days around the introduction of the XLP Program.

\begin{tabular}{|c|c|c|c|c|c|}
\hline \multicolumn{6}{|c|}{ Contribution of the Main Venue to the Consolidated Market } \\
\hline \multicolumn{6}{|c|}{$\begin{array}{l}\text { This table reports the contribution of the main markets Xetra and Eu- } \\
\text { ronext to the aggregate turnover and liquidity in the consolidated market } \\
\text { for DAX } 30 \text { and CAC40 stocks averaged across } 50 \text { days before and } 50 \text { days } \\
\text { after the introduction of the XLP Program. }\end{array}$} \\
\hline & & Pre & Post & \%Change & $\mathrm{DiD}$ \\
\hline \multirow{2}{*}{ Market Share } & Xetra & $52.31 \%$ & $57.62 \%$ & $10.15 \%$ & \multirow{2}{*}{$6.86 \%$} \\
\hline & Euronext & $55.71 \%$ & $57.54 \%$ & $3.29 \%$ & \\
\hline \multirow{2}{*}{ EBBO Share } & Xetra & $53.70 \%$ & $59.24 \%$ & $10.32 \%$ & \multirow{2}{*}{$5.71 \%$} \\
\hline & Euronext & $61.94 \%$ & $64.80 \%$ & $4.61 \%$ & \\
\hline \multirow{2}{*}{$\operatorname{Depth}(10)$ Share } & Xetra & $60.17 \%$ & $64.92 \%$ & $7.90 \%$ & \multirow{2}{*}{$6.24 \%$} \\
\hline & Euronext & $62.12 \%$ & $63.15 \%$ & $1.66 \%$ & \\
\hline \multirow{2}{*}{ L1-Volume Share } & Xetra & $38.36 \%$ & $47.09 \%$ & $22.75 \%$ & \multirow{2}{*}{$19.77 \%$} \\
\hline & Euronext & $54.15 \%$ & $55.76 \%$ & $2.99 \%$ & \\
\hline
\end{tabular}

Table A.5: Contribution of the main venue to the consolidated market 50 days around the introduction of the XLP Program. 


\begin{tabular}{|c|c|c|c|c|c|}
\hline \multicolumn{6}{|c|}{ Changes in Liquidity and Turnover of the Consolidated Market } \\
\hline \multicolumn{6}{|c|}{$\begin{array}{l}\text { This table reports the analyzed turnover and liquidity measures of the con- } \\
\text { solidated market for DAX30 and CAC40 stocks averaged across } 50 \text { days } \\
\text { before and } 50 \text { days after the introduction of the XLP Program. Turnover } \\
\text { L1-Volume, and Depth(10) are reported in millions, relative spread is de- } \\
\text { noted in basis points. }\end{array}$} \\
\hline & & Pre & Post & \%Change & $\mathrm{DiD}$ \\
\hline \multirow{2}{*}{ Turnover } & DAX30 & 125.49 & 142.59 & $13.63 \%$ & \multirow{2}{*}{$-12.96 \%$} \\
\hline & $\mathrm{CAC} 40$ & 86.29 & 109.24 & $26.59 \%$ & \\
\hline \multirow{2}{*}{ Relative Spread } & DAX30 & 3.42 & 3.44 & $0.56 \%$ & \multirow{2}{*}{$1.74 \%$} \\
\hline & $\mathrm{CAC} 40$ & 3.20 & 3.16 & $-1.18 \%$ & \\
\hline \multirow{2}{*}{$\operatorname{Depth}(10)$} & DAX30 & 1.89 & 1.95 & $3.21 \%$ & \multirow{2}{*}{$2.65 \%$} \\
\hline & CAC40 & 1.35 & 1.36 & $0.56 \%$ & \\
\hline \multirow{2}{*}{ L1-Volume } & DAX30 & 0.17 & 0.19 & $7.78 \%$ & \multirow{2}{*}{$3.61 \%$} \\
\hline & CAC40 & 0.13 & 0.14 & $4.17 \%$ & \\
\hline
\end{tabular}

Table A.6: Changes in liquidity and turnover of the consolidated market 50 days around the introduction of the XLP Program.

\begin{tabular}{|c|c|c|c|c|c|}
\hline \multicolumn{6}{|c|}{ Changes in Liquidity and Turnover of the Main Venue } \\
\hline \multicolumn{6}{|c|}{$\begin{array}{l}\text { This table reports the analyzed turnover and liquidity measures of the mair } \\
\text { markets Xetra and Euronext averaged across } 10 \text { days before and } 10 \text { days } \\
\text { after the introduction of the XLP Program. Turnover, L1-Volume, L2to10- } \\
\text { Volume, and Depth(10) are reported in millions, relative spread is denotec } \\
\text { in basis points, and MinTickShare is shown in percent. }\end{array}$} \\
\hline & & Pre & Post & \%Change & $\mathrm{DiD}$ \\
\hline \multirow{2}{*}{ Turnover } & Xetra & 73.94 & 76.32 & $3.22 \%$ & \multirow{2}{*}{$-9.86 \%$} \\
\hline & Euronext & 51.71 & 58.48 & $13.08 \%$ & \\
\hline \multirow{2}{*}{ Relative Spread } & Xetra & 4.39 & 4.26 & $-3.11 \%$ & \multirow{2}{*}{$-2.22 \%$} \\
\hline & Euronext & 3.86 & 3.83 & $-0.90 \%$ & \\
\hline \multirow{2}{*}{$\operatorname{Depth}(10)$} & Xetra & 1.18 & 1.31 & $10.85 \%$ & \multirow{2}{*}{$12.54 \%$} \\
\hline & Euronext & 0.90 & 0.89 & $-1.69 \%$ & \\
\hline \multirow{2}{*}{ L1-Volume } & Xetra & 0.12 & 0.14 & $17.86 \%$ & \multirow{2}{*}{$17.49 \%$} \\
\hline & Euronext & 0.10 & 0.10 & $0.37 \%$ & \\
\hline \multirow{2}{*}{ L2to10-Volume } & Xetra & 2.95 & 3.16 & $6.82 \%$ & \multirow{2}{*}{$7.44 \%$} \\
\hline & Euronext & 1.94 & 1.93 & $-0.62 \%$ & \\
\hline \multirow{2}{*}{ MinTickShare } & Xetra & 34.35 & 34.59 & $0.69 \%$ & \multirow{2}{*}{$-3.22 \%$} \\
\hline & Euronext & 39.85 & 41.41 & $3.90 \%$ & \\
\hline
\end{tabular}

Table A.7: Changes in liquidity and turnover of the main venue ten days around the introduction of the XLP Program. 


\begin{tabular}{|c|c|c|c|c|c|}
\hline \multicolumn{6}{|c|}{ Contribution of the Main Venue to the Consolidated Market } \\
\hline \multicolumn{6}{|c|}{$\begin{array}{l}\text { This table reports the contribution of the main markets Xetra and Eu- } \\
\text { ronext to the aggregate turnover and liquidity of the consolidated market } \\
\text { for DAX } 30 \text { and CAC } 40 \text { stocks averaged across } 10 \text { days before and } 10 \text { days } \\
\text { after the introduction of the XLP Program. }\end{array}$} \\
\hline & & Pre & Post & \%Change & $\mathrm{DiD}$ \\
\hline \multirow{2}{*}{ Market Share } & Xetra & $55.13 \%$ & $56.31 \%$ & $2.14 \%$ & \multirow{2}{*}{$3.47 \%$} \\
\hline & Euronext & $56.20 \%$ & $55.45 \%$ & $-1.33 \%$ & \\
\hline \multirow{2}{*}{ EBBO Share } & Xetra & $59.70 \%$ & $59.71 \%$ & $0.03 \%$ & \multirow{2}{*}{$0.37 \%$} \\
\hline & Euronext & $65.82 \%$ & $65.59 \%$ & $-0.35 \%$ & \\
\hline \multirow{2}{*}{$\operatorname{Depth}(10)$ Share } & Xetra & $62.60 \%$ & $64.15 \%$ & $2.48 \%$ & \multirow{2}{*}{$2.86 \%$} \\
\hline & Euronext & $61.00 \%$ & $60.77 \%$ & $-0.38 \%$ & \\
\hline \multirow{2}{*}{ L1-Volume Share } & Xetra & $42.94 \%$ & $45.54 \%$ & $6.06 \%$ & \multirow{2}{*}{$5.98 \%$} \\
\hline & Euronext & $53.77 \%$ & $53.81 \%$ & $0.08 \%$ & \\
\hline
\end{tabular}

Table A.8: Contribution of the main venue to the consolidated market ten days around the introduction of the XLP Program.

\begin{tabular}{|c|c|c|c|c|c|}
\hline \multicolumn{6}{|c|}{ Changes in Liquidity and Turnover of the Consolidated Market } \\
\hline \multicolumn{6}{|c|}{$\begin{array}{l}\text { This table reports the analyzed turnover and liquidity measures of the con- } \\
\text { solidated market for DAX30 and CAC } 40 \text { stocks averaged across } 10 \text { days } \\
\text { before and } 10 \text { days after the introduction of the XLP Program. Turnover } \\
\text { L1-Volume, and Depth(10) are reported in millions, relative spread is de- } \\
\text { noted in basis points. }\end{array}$} \\
\hline & & Pre & Post & \%Change & $\mathrm{DiD}$ \\
\hline \multirow{2}{*}{ Turnover } & DAX30 & 133.29 & 135.73 & $1.83 \%$ & \multirow{2}{*}{$-12.98 \%$} \\
\hline & CAC40 & 91.85 & 105.45 & $14.81 \%$ & \\
\hline \multirow{2}{*}{ Relative Spread } & DAX30 & 3.36 & 3.25 & $-3.33 \%$ & \multirow{2}{*}{$-2.01 \%$} \\
\hline & $\mathrm{CAC} 40$ & 3.07 & 3.03 & $-1.32 \%$ & \\
\hline \multirow{2}{*}{$\operatorname{Depth}(10)$} & DAX30 & 1.96 & 2.10 & $7.34 \%$ & \multirow{2}{*}{$8.13 \%$} \\
\hline & CAC40 & 1.48 & 1.46 & $-0.79 \%$ & \\
\hline \multirow{2}{*}{ L1-Volume } & DAX30 & 0.18 & 0.20 & $9.86 \%$ & \multirow{2}{*}{$8.95 \%$} \\
\hline & CAC40 & 0.15 & 0.15 & $0.90 \%$ & \\
\hline
\end{tabular}

Table A.9: Changes in liquidity and turnover of the consolidated market ten days around the introduction of the XLP Program. 


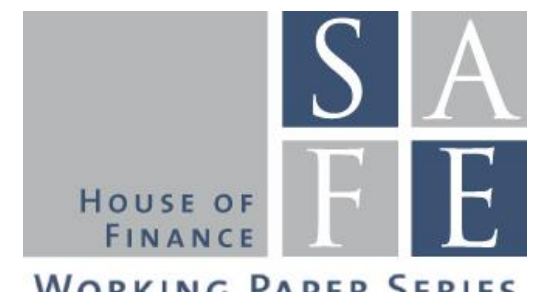

WORKING PAPER SERIES

\section{Recent Issues}

No. 230 Yalin Gündüz, Giorgio Ottonello, Loriana Pelizzon, Michael

Schneider, Marti G.

Subrahmanyam

No. 229 Daniel Harenberg

No. 228 Roberto C. Panzica

No. 227 Mila Getmansky, Ravi

Jagannathan, Loriana Pelizzon, Ernst Schaumburg, Darya Yuferova

No. 226 Loriana Pelizzon, Marti G.

Subrahmanyam, Davide Tomio, Jun Uno

No. 225 Monica Billio, Massimiliano

Caporin, Lorenzo Frattarolo, Loriana Pelizzon

No. 224 Giulio Girardi, Kathleen W. Hanley, Stanislava Nikolova, Loriana Pelizzon, Mila Getmansky Sherman

No. 223 Florian Deuflhard

No. 222 Vanessa Endrejat, Matthias Thiemann

No. 221 Axel H. Börsch-Supan, Klaus Härtl, Duarte N. Leite, Alexander Ludwig

No. 220 Yangming Bao, Martin R. Goetz

No. 219 Andreas Hackethal - Christine Laudenbach - Steffen Meyer Annika Weber
Lighting up the Dark: Liquidity in the German Corporate Bond Market

Asset Pricing in OLG Economies With Borrowing Constraints and Idiosyncratic Income Risk

Idiosyncratic Volatility Puzzle: The Role of Assets' Interconnections

Stock Price Crashes: Role of Slow-Moving Capital

Central Bank-Driven Mispricing?

Networks in risk spillovers:

A multivariate GARCH perspective

Portfolio Similarity and Asset Liquidation in the Insurance Industry

Quantifying Inertia in Retail Deposit Markets

Reviving the Shadow Banking Chain in Europe: Regulatory Agency, Technical Complexity and the Dynamics of CoHabitation

Endogenous Retirement Behavior of Heterogeneous Households Under Pension Reforms

Local Peer Effects and Corporate Investment

Client Involvement in Expert Advice Antibiotics in Finance? 